IO

RK

0

Personality Traits, Intra-household Allocation and the Gender Wage Gap

\author{
Christopher Flinn \\ Petra Todd \\ Weilong Zhang
}

Working Paper

2017-029

$04 / 2017$ 


\title{
Personality Traits, Intra-household Allocation and the Gender Wage Gap
}

\author{
Christopher J Flinn, Petra E Todd and Weilong Zhang *
}

February 15, 2017

\begin{abstract}
A model of how personality traits affect household time and resource allocation decisions and wages is developed and estimated. In the model, households choose between two modes of behavior: cooperative or noncooperative. Spouses receive wage offers and allocate time to supplying labor market hours and to producing a public good. Personality traits, measured by the so-called Big Five traits, can affect household bargaining weights and wage offers. Model parameters are estimated by Simulated Method of Moments using the Household Income and Labor Dynamics in Australia (HILDA) data. Personality traits are found to be important determinants of household bargaining weights and of wage offers and to have substantial implications for understanding the sources of gender wage disparities.
\end{abstract}

JEL: D1, J12, J16, J22, J31, J71

Keywords: gender wage differentials, personality and economic outcomes, household bargaining, time allocations

${ }^{*}$ Christopher Flinn is Professor of Economics at New York University and at Collegio Carlo Alberto, Italy. Petra Todd is Edmund J. and Louise W. Kahn Term Professor of Economics at the University of Pennsylvania and a member of the U Penn Population Studies Group, NBER and IZA. Weilong Zhang is a PhD student in the U Penn economics department. 


\section{Introduction}

Early models of household decision-making specified a unitary model that assumed that a household maximizes a single utility function. (e.g. Becker (1981)) In recent decades, however, researchers have made substantial progress towards modeling the household as a collection of individual agents with clearly delineated preferences, which permits consideration of questions related to the distribution of resources within the household. The agents are united through the sharing of public goods, through joint production technologies for producing public goods, through shared resource constraints, and through preferences. One approach is the cooperative approach that allows for differences between spouses to affect household decisionmaking by specifying a sharing rule or the Pareto weights which is essentially a household social welfare function. Cooperative models assume that the household reaches Pareto efficient outcomes. Variations in the class of cooperative models specify different ways in which households reach a particular point on the Pareto frontier (e.g. Manser and Brown (1980), McElroy and Horney (1981), and Chiappori (1988)). An alternative approach assumes that the household members act noncooperatively. This approach is also based on a model with individual preferences, but assumes that realized outcomes are determined by finding a Nash equilibrium using the reaction functions of the household members. These equilibria are virtually never Pareto efficient (e.g. Lundberg and Pollak (1993), Bourguignon (1984), Del Boca and Flinn (1995)).

In reality, it is likely that different households behave in different ways and even that the same household might behave differently at different points in time. One of the few studies to combine these different modeling approaches into one paradigm is Del Boca and Flinn (2012). Their study estimates a model of household time allocation, allowing for both efficient and inefficient household modes of interaction. In their model, two spouses allocate time to market work and to producing a public good and their decisions are repeated over an indefinitely long time horizon. The model incorporates incentive compatibility constraints that require the utility of each household member to be no lower that it would be in the (non cooperative) Nash equilibrium. Del Boca and Flinn (2012) find that the constraints are binding for many households and that approximately one-fourth of households behave in an inefficient manner.

This paper adopts a cooperative/noncooperative modeling framework similar to that of Del Boca and Flinn (2012), but our focus is on understanding the role of

personality traits in affecting household time allocation decisions and labor market outcomes. Personality trait measures aim to capture "patterns of thought, feel- 
ings and behavior" that correspond to "individual differences in how people actually think, feel and act" (Borghans et al. (2008)). The most commonly used measures, which are the ones used in this paper, are the so-called Big Five. They measure individual openness to experience, neuroticism (the opposite of emotional stability), extraversion, agreeableness, and conscientiousness. The model we develop and estimate incorporates public and private goods consumption, labor supply at the extensive and intensive margins, and time allocated to home production. Personality traits operate as potential determinants of household bargaining weights and wage offers.

There is an increasing recognition that non cognitive traits play an important role in explaining a variety of outcomes related to education, earnings, and health. Heckman and Raut (2016) and Heckman et al. (2006) argue that personality traits may have both direct effects on an individual's productivity and indirect effects by affecting preferences for schooling or occupation choices. A study by Fletcher (2013) finds a robust relationship between personality traits and wages using sibling samples. Specifically, conscientiousness, emotional stability, extraversion and openness to experience were all found to positively affect wages. Cubel et al. (2016) examine whether Big Five personality traits affect productivity using data gathered in a laboratory setting where effort on a task is measured. They find that individuals who exhibit high levels of conscientiousness and higher emotional stability perform better on the task.

Recent reviews of gender differences in preferences and in personality traits can be found in Croson and Gneezy (2009) and Marianne (2011). Studies across many different countries find that women are on average more agreeable and more neurotic than men and that gender differences in personality are associated with differences in wages. ${ }^{1}$ However, the most crucial traits in affecting wages differ by country. Using Dutch data, Nyhus and Pons (2005) find that emotional stability is positively associated with wages for both genders and agreeableness is associated with lower wages for women. Using data from the British Household Panel Study, Heineck (2011) analyzes correlations between big Five personality traits and wages and finds a positive relationship between openness to experience and wages as well as a negative linear relationship between agreeableness and wages for men. He also finds a negative relationship between neuroticism and wages for women. Mueller and Plug (2006), using data from the Wisconsin Longitudinal Study, find that nonagreeableness, openness and emotional stability are positively related to men's earnings, whereas conscientiousness and openness are positively related to women's earnings. They find that

\footnotetext{
${ }^{1}$ Women also exhibit differences in competitive attributes, risk aversion, preferences for altruism, and inequality aversion.
} 
the return that men receive for being nonagreeable is the most significant factor explaining the gender wage gap. Applying decomposition methods to data from the NLSY and using different measures of personality, Cattan (2013) finds that gender differences in self-confidence largely explain the gender wage gap, with the strongest effect being at the top of the wage distribution. ${ }^{2}$ Braakmann (2009), using German Socioeconomic Panel (GSOEP) data, finds that higher levels of conscientiousness increase the probability of being full-time employed for both genders, while higher levels of neurotism and agreeableness have the opposite effect.

It is only recently that survey data have been collected on the personality traits of multiple household members for large random samples, which permits analysis of how personality traits affect marriage and the division of labor/resources within the household. ${ }^{3}$ Lundberg (2012) notes that personality traits can shape preferences and capabilities that affect the returns to marriage and that they may also influence the ability of partners to solve problems and to make long-term commitments. Using data from the German Socioeconomic Panel (GSOEP), she finds that Big Five traits significantly affect the probability of marriage, the probability of divorce, and the duration of marriage. Using data from the Netherlands, Dupuy and Galichon (2014) show that Big Five personality traits are significant determinants of marriage matches and that different traits matter for men and women.

In this paper, we use a structural behavioral model to explore the extent to which personality traits of husbands and wives affect household time and resource allocation decisions. In particular, we examine how personality traits affect the mode of interaction the household adopts (cooperative or noncooperative), the amount of labor each spouse supplies to home production and market work, the provision of public goods, wage offers and accepted wages. Our analysis focuses on couples where the head of the household is age 30-50, because education and personality traits have largely stabilized by age 30 . The model is static and takes the observed marriage sorting patterns as given. Individuals with different educational attainment and personality traits may form different households. In the model, spouses have their own preferences over consumption of a private good and a public good. They choose the amount of time to allocate to market work and to the production of a public good, and there is a production technology that specifies how household members' time translates into public good production. The model incorporates household bargaining

\footnotetext{
${ }^{2}$ The National Longitudinal Survey of Youth Data do not contain measurements on the Big Five personality traits

${ }^{3}$ Examples include the British Household Panel Study (BHPS), the German Socioeconomic Panel (GSOEP), and Household Income and Labor Dynamics in Australia (HILDA), from which the data used in this paper are drawn.
} 
weights that may depend on the personality characteristics of both spouses, their education levels, ages, and cognitive abilities. ${ }^{4}$

We use data from the Household Income and Labor Dynamics survey in Australia (HILDA). An unusual feature of these data relative to other available data bases is that they contain the Big Five personality measures at three points in time (over a span of eight years) for multiple household members. In addition to the personality trait measures, we also use information on age, gender, educational attainment, wages, hours worked, and time spent engaging in home production.

Model parameters are estimating using the Method of Simulated Moments. The moments pertain to wages, labor market hours, housework hours and labor force participation of different types of households. Model parameters are chosen to minimize the weighted distance between moments simulated using the data generating process from the model and moments based on the data.

This paper analyzes male-female earnings differentials within a model of household decision-making. The vast majority of papers in the gender earnings gap literature (e.g. Altonji and Blank (1999), Blau and Kahn (1997, 2006); Autor et al. (2008)) consider male and female earnings without recognizing that the majority of adults are tied to individuals of the opposite sex through marriage or cohabitation. There are a few papers, however, that analyze male and female labor supply decisions and wage outcomes within a household framework. For example, Gemici (2011) analyzes household migration decisions in response to wage offers that males and females receive from different locations. Gemici and Laufer (2011) studies household formation, dissolution, labor supply, and fertility decisions. Tartari (2015) studies the relationship between children's achievement and the marital status of their parents within a dynamic framework in which partners decide on whether to remain married, how to interact (with or without conflict), on labor supply and on child investments. Joubert and Todd (2016) analyze household labor supply and savings decisions within a collective household model, with a focus on the gender gap in pension receipt.

Within a household framework, the manner in which household decisions are made impacts the likelihood that a man or woman will be in the labor market, the hours supplied, and their earnings. Given the assumptions of our model concerning male and female preferences, wage offer distributions, and the method of determining household allocations, we are able to assess the impact of individual and household characteristics not only on observed gender differences in wages, but also the utility realizations of household members. Below, we will show that gender differences in utility levels of males and females inhabiting households together are more important

\footnotetext{
${ }^{4}$ This formulation differs from Del Boca and Flinn (2012).
} 
indicators of systematic gender differences than are differences in observed wage rates.

Our analysis yields a number of potentially important findings. First, personality traits are significant determinants of household bargaining weights and of offered wages. Second, men and women have different traits on average and their traits are valued differently in the labor market as reflected in estimated wage offer equations. The effect of personality on offered wages is comparable in magnitude to the effect of education. Third, decomposition results show that gender differences in market valuations of personality traits largely explain observed wage gaps. We find that if women were paid according to the male wage offer equation, the gap in accepted wages would be eliminated. Fourth, we find that the gender gap in accepted wages is smaller than the gap in offered wages, and this difference arises because of the differences in the labor market participation decisions of husbands and wives. We find that women are more selective than men in accepting employment. Fifth, we find that 37.5 percent of households choose to behave cooperatively, which also affects working decisions. Cooperation tends to increase the desired level of household public goods, which require both time and monetary investments, and therefore tends to increase the labor supply of both men and women. Sixth, the marriage market exhibits positive assortative matching on personality traits, which tends to increase gender gaps in accepted wages relative to what it would be if spouses were randomly matched.

The rest of the paper is structured as follows. In the next section we present our baseline model. Section 3 describes the data used. Section 4 describes the econometric specification and estimation implementation. In section 5 and section 6 , we present the estimation results and counterfactual experiments. We conclude in section 7 .

\section{$2 \quad$ Model}

We begin by describing the preferences of the household members and the household production technology. Next, we describe the cooperative and noncooperative

solutions to the model. The section concludes with an examination of the choice of the household members to behave cooperatively or not, and the potential role that personality traits play in this decision. 


\subsection{Preferences and Household Production Technology}

A household is formed with a husband and a wife, distinguished by subscripts $m$ and $f$, respectively. Each individual has a utility function given by

$$
\begin{aligned}
U_{m} & =\lambda_{m} \ln l_{m}+\left(1-\lambda_{m}\right) \ln K \\
U_{f} & =\lambda_{f} \ln l_{f}+\left(1-\lambda_{f}\right) \ln K
\end{aligned}
$$

where $\lambda_{m}$ and $\lambda_{f}$ are both elements within $(0,1), l_{j}$ denotes the leisure of spouse $j(j=m, f)$, and $K$ is the quantity of produced public good. The household production technology is given by

$$
K=\tau_{m}^{\delta_{m}} \tau_{f}^{\delta_{f}} M^{1-\delta_{m}-\delta_{f}},
$$

where $\tau_{j}$ is the housework time of spouse $j, \delta_{j}$ is a Cobb-Douglas productivity parameter specific to spouse $j$, and $M$ is the total income of the household. Income $M$ depends on the labor income of both spouses as well as nonlabor income:

$$
M=w_{m} h_{m}+w_{f} h_{f}+y_{m}+y_{f}
$$

Here, $w_{j}$ is the wage rate of spouse $j, h_{j}$ is the amount of time that the supply to the labor market, and $y_{j}$ is their amount of nonlabor income. The time constraint of each spouse is given by

$$
T=\tau_{j}+h_{j}+l_{j}, j=m, f .
$$

A few comments are in order concerning this model specification. We have assumed that all of the choice variables relate to time allocation decisions, with no explicit consumption informations. This is standard since most data sets utilized by microeconomists contain fairly detailed information on labor market behavior and some information on housework, with little in the way of consumption data. We have made Cobb-Douglas assumptions regarding individual preferences and the household production technology. Because we assume that there exists heterogeneity in the preference parameters, $\lambda_{m}$ and $\lambda_{f}$, and the production function parameters, $\delta_{m}$ and $\delta_{f}$, we are able to fit patterns of household behavior very well, even under these restrictive functional forms. ${ }^{5}$

\footnotetext{
${ }^{5}$ Del Boca and Flinn (2012) actually estimate the distribution of the individual characteristics nonparametrically, and show that by doing so the model is "saturated." That is, there are the same number of free parameters as there are data points. Model fit is perfect in such a case. For the purposes of this exercise, we assume that these characteristics follow a parametric distribution, but we utilize one that is flexible and capable of fitting patterns in the data quite accurately.
} 
To this point, we have largely followed Del Boca and Flinn (2012); Del Boca et al. (2014). Our point of departure is the addition of personality traits to their formulation, and in adding a wage equation to the model. Del Boca and Flinn (2012) did not have to estimate a wage function, because they restricted their sample to include only households in which both spouses work. In their case, they did not have to estimate a wage equation; they simply conditioned on the observed wages of the husbands and wives. Because one of the main focuses of our analysis is to examine the impact of personality traits on household behavior and on a woman's decision to participate in the labor market, it is necessary for us to estimate wage equations for both husbands and wives. Let $x_{j}$ denote observable characteristics of spouse $j$ and $\theta_{j}$ the personality characteristics of spouse $j$. Then a household is characterized by the state vector

$$
S_{m, f}=\left(\lambda_{m}, \delta_{m}, w_{m}, y_{m}, \theta_{m}, x_{m}\right) \bigcup\left(\lambda_{f}, \delta_{f}, w_{f}, y_{f}, \theta_{f}, x_{f}\right)
$$

Given $S_{m, f}$, either mode of behavior is simply a mapping

$$
\left(\tau_{m}, h_{m}, l_{m}, \tau_{f}, h_{f}, l_{f}\right)=\Psi_{E}\left(S_{m, f}\right), E=N C, P W
$$

where $E=N E$ is the (noncooperative) Nash equilibrium case and $E=P W$ is the (cooperative) Pareto weight case. We note that each spouses' wage offer $w_{j}$ is observed by the household, but the analyst will not observe $w_{j}$ if $h_{j}=0$. Certain elements of $S_{m, f}$ may not play roles in the determination of equilibrium outcomes in certain behavioral regimes. We now turn to a detailed description of these solutions.

\subsection{Non-Cooperative Behavior}

In the noncooperative regime, personality characteristics play no role, primarily because the nature of interaction between the spouses is limited. Under our modeling assumptions, Del Boca and Flinn (2012) show that there exists a unique equilibrium solution in reaction functions, at least in the cases in which spouses are both in or both out of the labor market. ${ }^{6}$ Because ours is a model of complete information, each spouse is fully aware of the other's preferences, productivity characteristics, wage offer, and non-labor income. The decisions made by each spouse are best responses to the other spouse's choices, and are (most often) unique and stable. In this environment, little communication and interaction between the spouses is required.

\footnotetext{
${ }^{6}$ Because Del Boca and Flinn $(2012,2014)$ conditioned their analysis on the fact that both spouses were in the labor market, the noncooperative solution was unique.
} 
Each spouse makes three time allocation choices. Because they must sum to $T$, it is enough to describe the equilibrium in terms of each spouse's choices of labor supply and housework time. The reaction functions given the state vector $S_{m, f}$ are

$$
\begin{aligned}
& \left\{h_{m}(N E), \tau_{m}(N E)\right\}\left(h_{f}, \tau_{f} ; S_{m, f}\right)=\arg \max _{h_{m}, \tau_{m}} \lambda_{m} \ln l_{m}+\left(1-\lambda_{m}\right) \ln K \\
& \left\{h_{f}(N E), \tau_{f}(N E)\right\}\left(h_{m}, \tau_{m} ; S_{m, f}\right)=\arg \max _{h_{f}, \tau_{f}} \lambda_{f} \ln l_{f}+\left(1-\lambda_{f}\right) \ln K,
\end{aligned}
$$

where

$$
K=\tau_{m}^{\delta_{m}} \tau_{f}^{\delta_{f}}\left(w_{m} h_{m}+w_{f} h_{f}+Y_{m}+Y_{f}\right)^{1-\delta_{m}-\delta_{f}}
$$

For $\lambda_{j} \in(0,1), j=m, f$, and $0<\delta_{m}, 0<\delta_{f}$, and $\delta_{m}+\delta_{f}<1$, Del Boca and Flinn (2012) show that there is a unique equilibrium for their case in which both spouses in the households supply labor to the market. However, if we remove the constraint that the Nash equilibrium always results in both spouses choosing to supply a positive amount of time to the labor market, there is the possibility of multiple equilibria arising. The multiple equilibria occur due to the constraint that working hours are nonnegative for both spouses. There can be at most two Nash equilibria, with each having only one of the spouses supplying a positive amount of time to the market, and the other in which the spouses switch roles in terms of who is supplying time to the market and who isn't. When both supply time to the market, the equilibrium is unique, as it is when neither supplies time to the market. Furthermore, it is the case that when either supplies time to the market and the other does not, the equilibrium may either be unique or not. Given the structure of the model and the estimated parameters, the frequency of multiple equilibria is small. However, when they do occur, a position must be taken as to which of the two equilibria are selected. We will follow convention and assume that the equilibrium in which the male participates and the female does not is the one selected. ${ }^{7}$

The utility value of this equilibrium to spouse $j$ is given by

$$
V_{j}(N E)=\lambda_{j} \ln \left(T-h_{j}(N E)-\tau_{j}(N E)\right)+\left(1-\lambda_{j}\right) \ln K(N E), j=m, f,
$$

with

$$
K(N E)=\tau_{m}(N E)^{\delta_{m}} \tau_{f}(N E)^{\delta_{f}}\left(w_{m} h_{m}(N E)+w_{f} h_{f}(N E)+Y_{m}+Y_{f}\right)^{1-\delta_{m}-\delta_{f}},
$$

where we have supressed the dependence of the equilibrium outcomes on the state vector $S_{m, f}$ to avoid notational clutter.

\footnotetext{
${ }^{7}$ Alternatively, one could allow the selection mechanism, which is arbitrary in any case, to depend on personality characteristics. We intend to pursue this idea in our future research on the subject.
} 


\subsection{Cooperative Behavior}

The Benthamite social function for the household with the Pareto weight $\alpha$ is given by

$$
\begin{gathered}
W\left(h_{m}, h_{f}, \tau_{m}, \tau_{f} ; S_{m, f}\right)=\alpha\left(S_{m, f}\right) U_{m}\left(h_{m}, h_{f}, \tau_{m}, \tau_{f} ; S_{m, f}\right) \\
+\left(1-\alpha\left(S_{m, f}\right)\right) U_{f}\left(h_{m}, h_{f}, \tau_{m}, \tau_{f} ; S_{m, f}\right),
\end{gathered}
$$

where we have eliminated the leisure choice variable $l_{j}, j=f, m$ by imposing the time constraint. The Pareto weight $\alpha\left(S_{m, f}\right) \in(0,1)$, and, as the notation suggests, will be allowed to be a function of a subset of elements of $S_{m, f}$. In the cooperative (efficient) regime, the household selects the time allocations that maximize $W$, or

$$
\left(h_{m}, h_{f}, \tau_{m}, \tau_{f}\right)\left(S_{m, f}\right)=\arg \max _{h_{j}, \tau_{j}, j=m, f} W\left(h_{m}, h_{f}, \tau_{m}, \tau_{f} ; S_{m, f}\right) .
$$

Because this is simply an optimization problem involving a weighted average of two concave utility functions, the solution to the problem is unique. Then the utility levels of the spouses under cooperative behavior is

$$
V_{j}(P W)=\lambda_{j} \log \left(T-h_{j}(P W)-\tau_{j}(P W)\right)+\left(1-\lambda_{j}\right) \log K(P W), j=m, f,
$$

with

$$
K(P W)=\tau_{m}(P W)^{\delta_{m}} \tau_{f}(P W)^{\delta_{f}}\left(w_{m} h_{m}(P W)+w_{f} h_{f}(P W)+Y_{m}+Y_{f}\right)^{1-\delta_{m}-\delta_{f}} .
$$

Once again, we have suppressed the dependence of solutions on the state variable vector $S_{m, f}$. In the cooperative model, there is no danger of multiple equilibria, since it is not really an equilibrium specification at all, but simply a household utilitymaximization problem.

\subsection{Selection Between the Two Allocations}

Del Boca and Flinn (2012) constructed a model in which the Pareto weight, $\alpha$, was "adjustable" so as to satisfy a participation constraint for each spouse that enforced

$$
V_{j}(P W) \geq V_{j}(N E), j=m, f .
$$

With no restriction on the Pareto weight parameter $\alpha$, the $V_{j}(P W)$ could be less than $V_{j}(N E)$ for one of the spouses (it always must exceed the noncooperative value for at least one of the spouses). For example, if $V_{m}(P W)<V_{m}(N E)$, the husband 
has no incentive to participate in the "efficient" outcome, because he is worse off under it. To give him enough incentive to participate, the value of $\alpha$, which is his weight in the social welfare function, is increased to the level at which he is indifferent between the two regimes. Meanwhile, his spouse with the "excess" portion of the household surplus from cooperation has to cede some of her surplus by reducing her share parameter, $(1-\alpha)$ in this case, to the point at which the husband is indifferent between the two regimes.

In such a world, and in a static context, an efficient outcome could always be achieved through adjustment of the Pareto weight. As a result, all households would behave cooperatively. To generate the possibility that some households would behave noncooperatively, the Del Boca and Flinn assumed a pseudo-dynamic environment, in which the spouses played the same stage game an infinite number of times. They assumed a grim-trigger strategy, so that deviations from the agreed upon cooperative outcome would result in a punishment state in which the Nash equilibrium would be played in perpetuity. Using Folk Theorem results and with the estimation of a common discount factor used by all agents in the population, they estimated that approximately 25 percent of households in their sample behaved in a noncooperative manner.

In our model, which focuses on the role of personality traits in explaining wage and welfare differences between husbands and wives, we think of the Pareto weight $\alpha$ as being determined, in part, by the personality characteristics of the husband and wife. For example, someone who is very agreeable and who is married to a nonagreeable person might receive a lower Pareto weight. In this case, it is somewhat more problematic to assume that the $\alpha$ can be freely adjusted to satisfy the participation constraint of one of the spouses. For this reason, we assume that the value of $\alpha$ is fixed. This simplifies the cooperative versus noncooperative decision of the household, as well as the computation of the model. It also serves to stress the fact that the personality characteristics of both spouses will play a factor in how they settle on a particular mode of behavior. ${ }^{8}$

A household will behave cooperatively if and only if both of the following weak inequalities hold:

$$
\begin{aligned}
V_{m}(P W) & \geq V_{m}(N E) \\
V_{f}(P W) & \geq V_{f}(N E) .
\end{aligned}
$$

\footnotetext{
${ }^{8}$ In a more elaborate model, we could imagine a situation in which the Pareto weight could be adjusted, but with a cost depending on the personality characteristics of the spouses. From this perspective, we are assuming that the costs of adjusting the Pareto weight are indefinitely large for one or both of the spouses.
} 
Thus, there is no scope for "renegotiation" in this model. There is a positive probability that any household behaves cooperatively that is strictly less than one given our specification of preference heterogeneity. The simplest way to characterize the cooperation decision in our framework is as follows. We begin by explicitly including the value of $\alpha$ in the cooperative payoff function for household $j$, so that

$$
V_{j}\left(P W \mid S_{m, f}, \alpha\right), j=m, f .
$$

Given that the function $V_{m}\left(P W \mid S_{m . f}, \alpha\right)$ is monotonically increasing in $\alpha$ and given that $V_{f}\left(P W \mid S_{m, f}, \alpha\right)$ is monotonically decreasing in $\alpha$, we can define two critical values, $\underline{\alpha}^{*}\left(S_{m, f}\right)$ and $\bar{\alpha}^{*}\left(S_{m, f}\right)$ such that

$$
\begin{aligned}
V_{m}\left(P W \mid S_{m, f}, \underline{\alpha}^{*}\left(S_{m, f}\right)\right) & =V_{m}\left(N E \mid S_{m, f}\right) \\
V_{f}\left(P W \mid S_{m, f}, \bar{\alpha}^{*}\left(S_{m, f}\right)\right) & =V_{f}\left(N E \mid S_{m, f}\right) .
\end{aligned}
$$

The set of $\alpha$ values that produce cooperative behavior in the household is connected, so that the household will behave cooperatively if and only if

$$
\alpha\left(S_{m, f}\right) \in\left[\underline{\alpha}^{*}\left(S_{m, f}\right), \bar{\alpha}^{*}\left(S_{m, f}\right)\right] .
$$

For a given value of the state variables, $S_{m, f}$, the household will either behave cooperatively or not; there is no further stochastic element in this choice after we have conditioned on $S_{m, f}$. The probabilistic nature of the choice is due to the randomness of $S_{m, f}$. Although some elements of $S_{m, f}$ are observable (and do not include measurement error under our assumptions), others are not. There are a subset of elements that are not observed for any household, which include the preference and household production parameters. We denote the set of unobserved household characteristics by $S_{m, f}^{u}=\left\{\lambda_{m}, \delta_{m}, \lambda_{f}, \delta_{f}\right\}$, with the set of (potentially) observed characteristics given by $S_{m, f}^{o}=\left\{w_{m}, y_{m}, \theta_{m}, x_{m}, w_{f}, y_{f}, \theta_{f}, x_{f}\right\}$. We say that these elements are all potentially observable because the wage offers, $w_{j}, j=m, f$, are only observed if spouse $j$ supplies a positive amount of time to the labor market. The state variable vector $S_{m, f}^{o}(i)$ that is observed for household $i$ will have a degenerate marginal distribution. The unobserved vector $S_{m, f}^{u}(i)$ will always have nondegenerate marginal distributions. Let the distribution of $S_{m, f}^{u}(i)$ be given by $G_{i}$, and assume that $G_{i}=G$ for all $i$. Then the probability that household $i$ is cooperative is simply the measure of the set of $S_{m, f}^{u}(i)$ such that the cooperation condition is satisfied, or

$$
P\left(P W \mid S_{m, f}^{o}(i)\right)=\int \chi\left[\underline{\alpha}^{*}\left(S_{m, f}(i)\right) \leq \alpha\left(S_{m, f}(i)\right) \leq \bar{\alpha}^{*}\left(S_{m, f}(i)\right)\right] d G\left(S_{m, f}^{u}\right) .
$$


For any household $i, 0<P\left(P W \mid S_{m, f}^{u}(i)\right)<1$, due to what is essentially a full support condition. The preference weight on leisure for spouse $j$ lies in the interval $(0,1)$. As $\lambda_{j} \rightarrow 1$, spouse $j$ only cares about leisure and gives no weight to the public good. In the Nash equilibrium, their contribution to household production through time and money will converge to 0 , and the cooperative solution, which results in greater production of the public good, will be of no value to them. As $\lambda_{j} \rightarrow 0$, the individual will demand little leisure and will spend all of their time in the labor market and household production. For cases in which $\lambda_{m}$ and $\lambda_{f}$ are both arbitrarily close to 1 , the household will be noncooperative. For cases, in which $\lambda_{m}$ and $\lambda_{f}$ are close to 0 , the household will be cooperative. Thus, independently of the other values in the state vector, variability in the preference parameters on the full support of their (potential) distribution is enough to guarantee that no household can be deterministically classified as cooperative a priori.

\section{Data Description}

\subsection{Selection of the Estimation Sample}

We use sample information from the Household Income and Labour Dynamics in Australia (HILDA) longitudinal data set. HILDA is a representative one in one thousand sample of the Australian population. It is an ongoing longitudinal annual panel starting in the year 2001 with 19,914 initial individuals from 7,682 households. (Summerfield et al. (2015)) Our paper makes use of variables in the following categories: (1) labor market outcomes including annual labor earnings and working hours; (2) housework split information; (3) self-completion life style questions such as the fairness of housework arrangement; (4) education levels ranging from senior secondary school until the highest degree; and the (5) "Big Five" personality traits assessment collected three times, in waves 5, 9, and 13, and cognitive ability collected once in wave 12 .

To the best of our knowledge, HILDA has the highest quality information on personality traits among all nationwide data sets. ${ }^{9}$ For the majority of respondents, we observe three repeated measurements of personality traits over an eight-year time window. As described in Section1, the measurements of personality traits are based on the Five Factor ("Big Five") Personality Inventory, which classifies personality

\footnotetext{
${ }^{9}$ The only other two national-wide data sets providing personality traits inventory assessments are the German Socio-Economic Panel (GSOEP) study and the British Household Panel (BHPS) study. Both of them also collected "Big Five" measures.
} 
traits along five dimensions: Openness to Experience, Conscientiousness, Extraversion, Agreeableness, and Emotional Stability (?). "Big Five" information in HILDA is constructed by using responses to 36 personality questions, which is fully displayed in table $1 .{ }^{10}$ Respondents were asked to pick a number from 1 to 7 to assess how well each personality adjective describes them. The lowest number, 1 , denotes a totally opposite description and the highest number, 7 , denotes a perfect description. According to Losoncz (2009), only 28 of 36 items load well into their corresponding components when performing factor analysis. The other 8 items are discarded due to either their low loading values or their ambiguity in defining several traits. ${ }^{11}$ The construction of the "Big Five" follows the procedure provided by Losoncz (2009). We include all individuals who have at least one personality trait measurement. For the individuals whose personality traits are repeatedly surveyed, the average values are used.

In addition to the information on personality traits, HILDA also collected information on cognitive ability once in wave $12 .{ }^{12}$ We construct a one-dimensional measure of cognitive ability from three different measures: (i) Backward Digits Span, (ii) Symbol Digits Modalities and (iii) a 25-item version of the National Adult Reading Test.

We focus our attention on households whose heads are between the ages of 30 to age 50, inclusive, for two reasons. First, household structure may change dramatically during earlier ages due to the potential marriage and fertility events. Second, personality traits are more malleable when people are young and stabilize as they age. Terracciano et al. (2006) and Terracciano et al. (2010) report that intra-individual stability increases up to age 30 and thereafter stabilizes. Thus we can reasonably treat a spouse's personality traits as being fixed after age 30 .

For the purposes of estimation, we only select one period of observation of those intact households where both husband and wife are present and the age of the household head is between 30 and 50. If we observe multiple periods within this age range, we pick the observation period closest to age $40 .{ }^{13}$ We exclude all households with

\footnotetext{
${ }^{10}$ The source of these 36 adjectives come from two parts. Thirty of them are extracted from Trait Descriptive Adjectives - 40 proposed by Saucier (1994), which is a selected version of Traits Descriptive Adjective - 100 (Goldberg (1992)) to balance the time use and accuracy. And the other additional six items comes from various resources.

${ }^{11}$ The way to check each item's loading performance is to calculate the loading value after doing oblimin rotation. The loading values of 8 abandoned items were either lower than 0.45 , or did not load more than 1.25 times higher on the expected factor than any other factor.

${ }^{12}$ According to the report of Wooden (2013), the response rate is high, approximately $93 \%$.

${ }^{13}$ We always pick the observation at age 40 if this period is available. Otherwise, we choose the period closest to age 40. For example, if the a household is in the panel when the head is ages 37 ,
} 
any dependents below age 14, because their household production substantially differs from the production of households without any young children. We also drop households for which housework hours or labor market hours information are missing. The hourly wage is calculated by dividing annual earnings by annual working hours. We also truncated the top five percent of hourly wage rates to eliminate what we took to be unrealistically high values. We set the total time available for leisure, housework, and labor supply in a week, $T$, to 112 (16 hours a day for seven days a week). Working time and housework hours both have an upper bound of 56 hours. Lastly, we dropped households for which personality trait or cognitive ability information is incomplete or missing altogether. The total number of household observations used in estimation is 973 .

\subsection{Key Variables: Wages, Time Allocations, Cognitive Abil- ity, and Personality Traits}

Table 2 describes the key variables. Given the sample selection process, it is not surprising that the average age of males is approximately 40 and the average age of females about 2 years younger. As is typically found, husbands spend more time in the labor market than do their wives. The employment rate for males is 94 percent and the average number of working hours (conditional on working) is 43.99 hours per week, while the employment rate of females is 87 percent and the average number of working hours (conditional on working) is 36.29 hours per week. As is found in virtually all countries and time periods, wives tend to spend significantly more time in housework than do husbands. The average of housework hours supplied by the husband is 15.39 hours, compared with the average of 20.91 hours of the wives. On average, husbands have 7.7 hours of labor supply more than their wives, but on average spend 5.6 fewer hours on housework. ${ }^{14}$ Under the assumption that the total time endowment per week is 112 hours, about one-half of the total time is spent in leisure for both males and females. The distributions of working hours and housework hours for wives are more dispersed than those for husbands. Their accepted wages are also lower. In general, the time allocations described in our paper using the HILDA dataset are consistent with patterns described in Del Boca and Flinn (2012);

38 , and 39 , we utilize the information for the wave in which the head was aged 39 .

${ }^{14}$ The definition housework time is the summation of hours devoted to errands, housework, outdoor tasks, playing with children and caring for a disabled spouse or elderly parents. However, given the exclusion of the households with dependent below age 14, the contribution from children-related actives is very limited. We put this restriction in order to get a more homogeneous interpretation of public good production function. 
Del Boca et al. (2014) using US PSID data (the 2005 wave).

With regard to personality traits and cognitive ability, we find significant gender differences. On average, men have lower scores on agreeableness, extraversion and conscientiousness compared with women. However, the gender differences in openness to experience and emotional stability are less significant. In our sample, wives have higher cognitive scores than husbands. These patterns are generally in line with findings reported in other studies.

We estimated a preliminary OLS regression to examine the relationship between measured personality traits and log wages (for those who were working) and their relationship with labor participation decisions. The regression results with the log wage as the dependent variable are shown in the first two columns in Table 3 . We find that men and women with high education and high cognitive ability have higher wages. In addition, conscientiousness increases wages for men and extraversion increases wages for women. The dependent variable is the labor participation dummy in the last two columns in Table 3. Higher education and cognitive scores are associated with higher rates of labor force participation for both men and women. The only personality trait that has a statistically significant effect on labor force participation is conscientiousness, which increases labor force participation for women.

\subsection{Assortative Matching of Personality Traits}

Although our paper does not explicitly model the marriage market and the manner in which men and women are paired in marriages, we are able to examine marital sorting on personality traits and cognitive scores using data on sample households. Figure 1 displays the scatter plots of spousal personality traits as well as cognitive abilities. We observe a strong positive assortative matching in the cognitive ability dimension with a correlation equal to 0.339. Among the "Big Five" personality traits, emotional stability and openness to experience are the traits that exhibit the most significant pattern of positive sorting (correlation larger than 0.1 ), whereas agreeableness has a less strong positive sorting pattern. There is no significant correlation in the extraversion and conscientiousness traits.

\subsection{Other Variables: Fair Share}

Despite the important role played by bargaining power (as typically represented by the Pareto weight), in cooperative models of the household, there is no direct mea-

surement of bargaining power proposed in the literature. The HILDA data provide a fairly high quality record of household activities. We consider the following question, 
completed by the respondent in the self-completion portion of the questionnaire, to be potentially related to the household allocation rule: "Do you think you do your fair share around the house?" The respondent has the option of choosing: (1) I do much more than my fair share. (2) I do a bit more than my fair share. (3) I do my fair share. (4) I do a bit less than my fair share. (5) I do much less than my fair share.

The distribution of fair share choices for both men and women is shown in table 4. A higher percentage of females report doing more than the fair share compared to males. The majority of husbands report that they do a fair share of housework, while the majority of wives report doing more than their fair share. The significantly negative correlation between men and women's report indicates that a better condition for the husband implies a worse condition for the wife, consistent with a Pareto weight interpretation.

We do not make direct use of the fair share variable in estimation. Rather, as described below, we will examine how simulations based on the estimated model relate to the fair share variable as a way of validating the model.

\section{Econometric Implementation}

As previously noted, a household $i$ is uniquely characterized by the vector $S_{m, f}(i)=$ $\left(\lambda_{i m}, \delta_{i m}, w_{i m}, y_{i m}, \theta_{i m}, x_{i m}\right) \bigcup\left(\lambda_{i f}, \delta_{i f}, w_{i f}, y_{i f}, \theta_{i f}, x_{i f}\right) .{ }^{15}{ }^{16}$ Given the vector $S_{m, f}(i)$, the equilibrium of the game that characterizes the time allocations of the household is uniquely determined. ${ }^{17}$ The wage equation for males and females comprising household $i$ is specified:

$$
\begin{gathered}
\ln w_{i m}=\gamma_{0 m}+\gamma_{1 m} \theta_{i m}+\gamma_{2 m} e_{i m}+\gamma_{3 m} c_{i m}+\epsilon_{i m} \\
\ln w_{i f}=\gamma_{0 f}+\gamma_{1 f} \theta_{i f}+\gamma_{2 f} e_{i f}+\gamma_{3 f} c_{i f}+\epsilon_{i f}
\end{gathered}
$$

The disturbances $\left(\epsilon_{i m} \epsilon_{i f}\right)$ are assumed to follow a joint normal distribution:

\footnotetext{
${ }^{15}\left\{\lambda_{i m}, \delta_{i m}, \lambda_{i f}, \delta_{i f}\right\}$ are the unobserved preferences and production technology of household $i$ drawn from distribution $G_{u}\left(S_{m, f}^{u}\right)$. $\left\{w_{i m}, y_{i m}, w_{i f}, y_{i f}\right\}$ are wages and other incomes in the household. Finally, $\left\{\theta_{i m}, x_{i m}, \theta_{i f}, x_{i f}\right\}$ are personality traits and other observed variables for both spouses $m$ and $f$.

${ }^{16}$ Given the information we have in the data, we include educational experience $e_{i j}$, age $a_{i j}$ and cognitive ability $c_{i j}, j=m, f$ as the observed variables $x_{i j}$.

${ }^{17}$ As noted above, in the noncooperative case, there is the possibility of two equilibria existing, one with the husband supplying time to the market and the wife not, and the other in which the wife works in the market and the husband does not. When these two equilibria exist, we use the convention that the one in which the male supplies time to the market is the one that is implemented.
} 


$$
\left[\begin{array}{c}
\epsilon_{i m} \\
\epsilon_{i f}
\end{array}\right] \sim N\left(\left[\begin{array}{l}
0 \\
0
\end{array}\right],\left[\begin{array}{cc}
\sigma_{\epsilon m}^{2} & \rho \sigma_{\epsilon m} \sigma_{\epsilon f} \\
\rho \sigma_{\epsilon m} \sigma_{\epsilon f} & \sigma_{\epsilon f}^{2}
\end{array}\right]\right)
$$

where $\sigma_{\epsilon m}$ denotes the standard deviation of the male's wage, $\sigma_{\epsilon f}$ denotes the standard deviation of the wife's wage, and $\rho$ denotes the correlation of the wage disturbances.

The model incorporates household heterogeneity in preferences and in the production technology by assuming the parameters, $\left(\lambda_{m} \lambda_{f} \delta_{m} \delta_{f}\right)$ are drawn from a joint distribution $G_{u}\left(S_{m, f}^{u}\right)$, where the $u$ subscript denotes the fact that these parameters are unobserved to the analyst, although they are assumed known by both spouses. The distribution $G_{u}$ is parametric, although it is "flexible" in the sense that it is characterized by a high-dimensional parameter vector. The distribution is created by mapping a four-dimensional normal distribution into the appropriate parameter space using known functions. Define the random vector $x_{4 \times 1} \sim N\left(\mu_{1}, \Sigma_{1}\right)$, where $\mu_{1}$ is $4 \times 1$ vector of means and $\sum_{1}$ is a $4 \times 4$ symmetric, positive-definite covariance matrix. The random variables $\left(\lambda_{m} \lambda_{f} \delta_{m} \delta_{f}\right)$ are then defined using the link functions

$$
\begin{gathered}
\lambda_{m}=\frac{\exp \left(x_{1}\right)}{1+\exp \left(x_{1}\right)} \\
\lambda_{f}=\frac{\exp \left(x_{2}\right)}{1+\exp \left(x_{2}\right)} \\
\delta_{m}=\frac{\exp \left(x_{3}\right)}{1+\exp \left(x_{3}\right)+\exp \left(x_{4}\right)} \\
\delta_{f}=\frac{\exp \left(x_{4}\right)}{1+\exp \left(x_{3}\right)+\exp \left(x_{4}\right)}
\end{gathered}
$$

The joint distribution of preference and production technology parameters, $\left(\lambda_{m}, \lambda_{f}, \delta_{m}, \delta_{f}\right)$, is fully characterized by 14 parameters.

We assume that the household Pareto weights may depend on education, cognitive scores and personality traits as well as the age of both spouses through the following parametric specification:

$$
\alpha(i)=\frac{Q_{m}(i)}{Q_{m}(i)+Q_{f}(i)},
$$

where

$$
Q_{j}(i)=\exp \left(\gamma_{4 j}+\gamma_{5 j} \theta_{j}(i)+\gamma_{6 j} e_{j}(i)+\gamma_{7 j} c_{j}(i)+\gamma_{8 j} a_{j}(i)\right), j=m, f .
$$

The coefficients of $\gamma_{5 j}, \gamma_{6 j}, \gamma_{7 j}, \gamma_{8 j}$ capture the effects of personality traits, education, cognitive ability and age on the Pareto weight of the husband. The Pareto weight of the wife is simply $1-\alpha(i)$, the weights are both positive and normalized so as to sum to 1 . 
Dividing both the numerator and denominator of $(1)$ by $Q_{f}(i)$, we have

$$
\alpha(i)=\frac{\tilde{Q}(i)}{1+\tilde{Q}(i)},
$$

where

$$
\begin{aligned}
\tilde{Q}(i) & =Q_{m}(i) / Q_{f}(i) \\
& =\exp \left(\sum_{k=4}^{8}\left[\gamma_{k m} z_{k m}(i)-\gamma_{k f} z_{k f}(i)\right]\right)
\end{aligned}
$$

where the index $k$ runs over all of the characteristics included in the $\alpha(i)$ function, and $z_{k j}(i) \equiv\left\{1, \theta_{j}(i), e_{j}(i), c_{j}(i), a_{j}(i)\right\}$ denotes the value of characteristic $k$ for gender $j$ in household $i$. We note that as long as the values of $z_{k j}(i)$ differ for men and women in a sufficiently large number of households, the parameters $\gamma_{k m}$ and $\gamma_{k f}$ are separately identified. With regard to the constant term, only the difference $\gamma_{4 m}-\gamma_{4 f}$ is identified.

In terms of examining the impact of a particular characteristic $z_{k}$ on the husband's Pareto weight, we define the term $\Gamma_{k}(i) \equiv \gamma_{k m} z_{k m}(i)-\gamma_{k f} z_{k f}(i)$, and compute the elasticity

$$
\eta_{k}(i)=\frac{\partial \alpha(i)}{\partial \Gamma_{k}(i)} \frac{\Gamma_{k}(i)}{\alpha(i)}, k=5, \ldots, 8
$$

for each household. In the results section below, we will present the distribution of these elasticities for each characteristic included in the $\alpha(i)$ function.

\subsection{Model estimation}

We estimate the model using a Simulated Method of Moments estimator. Given a set of parameters, we repeatedly draw from the distributions of household preference parameters, production function parameters, and potential wage offers, $\left(\delta_{m}^{s}, \lambda_{m}^{s}, w_{m}^{s}, \delta_{f}^{s}, \lambda_{f}^{s}, w_{f}^{s}\right)$, $N$ times for each household. Combined with other observed variables $\left(y_{m}, \theta_{m}, c_{m}, a_{m}, e_{m}, y_{f}, \theta_{f}, c_{f}, a_{m}, e_{f}\right)$, we solve for the time allocation of the household $\left(h_{f}^{s}, \tau_{f}^{s}, h_{f}^{s}, \tau_{f}^{s}\right)$. Model parameters are estimated by choosing the parameters that minimize the distance between the simulated sample moments and the real data moments using the quadratic distance function described below. The moments included in the estimator are described below.

Let $\Omega$ denote the parameter vector, $\tilde{M}_{s}(\Omega)$ denote the vector of moments from the simulations $\left(w_{m}^{s}, h_{m}^{s}, \tau_{m}^{s}, w_{f}^{s}, h_{f}^{s}, \tau_{f}^{s}\right)$ and $M_{N}$ denote the vector of moments from 
the observed data $\left(w_{m}, h_{m}, \tau_{m}, w_{f}, h_{f}, \tau_{f}\right)$. The optimal parameter vector $\Omega_{0}$ solves the objective function:

$$
\Omega_{0}=\arg \min _{\Omega}\left(\tilde{M}_{s}(\Omega)-M_{N}\right)^{\prime} W_{N}\left(\tilde{M}_{s}(\Omega)-M_{N}\right)
$$

where $W_{N}$ is the weight matrix constructed following Del Boca et al. (2014) by a resampling method. In particular, the resampled moment vector $M_{N}^{g}, g=1, \ldots, Q$ is calculated by bootstrapping the original data $Q$ times. ${ }^{18}$ Then the weight matrix is the inverse of the covariance matrix of $M_{N}$ :

$$
W_{n}=Q^{-1}\left(\sum_{g=1}^{Q}\left(M_{N}^{g}-M_{N}\right)\left(M_{N}^{g}-M_{N}\right)\right)^{-1} .
$$

\subsection{Principal component Analysis}

Because many of the parameters in the model are associated with personality traits, the moments used in estimation need to capture the relationship between choices, outcomes and personality traits. There are five traits, each of which can take on a large range of values, so that there are many possible moment conditions. To specify the moments used in estimation in a parsimonious way, we first apply principal-components analysis (PCA) to the five personality trait variables. We do the PCA separately for husbands and wives and retain the first two principal components, which have eigenvalues greater than 1, as shown in Table 5. For the first component, the most crucial loadings are conscientiousness, agreeableness and emotional stability $(.517, .543$ and .493$)$ in the male case. For women, all traits except openness to experience contribute almost equally to the first component. For the second component, loadings are concentrated on openness to experience for both males and females (.788 and .789). We then discretize the first two principal components into three levels (low, middle and high) and construct moments conditioning on these components and categories.

\subsection{Selection of Moments}

We estimated the above parameters by matching the following six groups of moments. They include: (1) Unemployment rate for men and women; (2) Mean and variance of working hours of workers employed on the market; (3) Mean and variance of home production hours; (4) Mean and variance of accepted wages; (5) Covariance

\footnotetext{
${ }^{18}$ We set $Q$ equal to 200.
} 
between men and women's time allocations; and (6) Covariance between men and women's accepted wages.

For moments 1-4 we use marginal moments conditional on educational level (college, no college), principal component 1 (low, middle and high) and principal component 2 (low, middle and high). However, for moments 5-6 we only use the unconditional moments.

\section{$5 \quad$ Estimation Results}

\subsection{Model estimates}

Table 6 reports the estimated model parameters. Part 1 (the upper panel) shows the effect of personality traits on wage offers and on the estimated Pareto weight for men and women. The return to education (conditional on the other included variables) is similar for women (0.0646) and men (0.0554). Of the personality traits, high values of conscientiousness and emotional stability significantly increase wage offers for men. A higher score on openness to experience leads to lower wages for men but higher wages for women. A higher score on agreeableness decreases wage offers for both men and women in a similar way. ${ }^{19}$ Cognitive ability has a larger positive impact on wage offers for men compared with its impact for women.

The household bargaining parameter is also significantly influenced by personality traits, education and cognitive ability. Although all the coefficients associated with the personality traits in the bargaining equation are negative, this does not mean that all personality traits have negative impact on Pareto weights. As mentioned previously, the relative difference between spouses rather than the absolute value is key in determining the Pareto weight.

To better understand how personality traits of both spouses affect the Pareto weight, we calculate the elasticity of Pareto weights with respect to the term $\Gamma_{k}(i) \equiv$ $\gamma_{k m} z_{k m}(i)-\gamma_{k f} z_{k f}(i)$, following the equation 2 mentioned in the last section:

$$
\eta_{k}(i)=\frac{\partial \alpha(i)}{\partial \Gamma_{k}(i)} \frac{\Gamma_{k}(i)}{\alpha(i)}, k=4, \ldots, 8
$$

\footnotetext{
${ }^{19}$ The asymmetric earning advantages associated with same personality traits are also documented by literatures. For example, Heineck and Anger (2010) find that openness to experience has positive effect for women but negative effect for men when estimating a mincer equation. Conscientiousness is tends to be positive for men but negative or insignificant for women. Although our sample (HILDA) differs from theirs (GSOEP), we generate similar gender differentials associated with the same traits.
} 
Figure 2 displays the distribution of $\Gamma_{k}(i)$ with respect to the Pareto weight $\alpha$. Among five personality traits, conscientiousness, emotional stability and agreeableness have the largest impact on average. For example, the average elasticity of agreeableness is -0.2678 . That is, the Pareto weight of husbands $(\alpha)$ increases $0.2678 \%$ on average if the gender difference for the evaluation of agreeableness $\gamma_{5 m}$ agreeableness $s_{m}(i)-\gamma_{5 f}$ agreeableness $_{f}(i)$ increases by $1 \%$. Similarly, conscientiousness has negative effect with average elasticity of -0.2632 whereas emotional stability has positive effect with average elasticity of 0.2410 . Lastly, we observe that educational attainment also significantly affects the Pareto weight, with a positive elasticity of 0.3578 on average.

Next, we explore how the Pareto weight affects the possibility of a household adopting a cooperative allocation. Table 7 displays the fraction of cooperative households under different values of $\alpha$. Although $\alpha$ has a possible range between [0,1], the Pareto weights of most households lie in the range [0.35,0.65], indicating the spouses in most households share fairly equal weights. Also, we observe that the households are more likely to adopt cooperative interaction mode when the Pareto weight is close to equal. Around $66.1 \%$ of households choose to play cooperatively when $\alpha \in[0.45,0.55)$, whereas none of households play cooperatively when the value of $\alpha$ is extreme $(\alpha>0.75$ or $\alpha<0.15)$.

We next describe the estimated distribution of the spousal preference and production parameters $\left\{\delta_{m}, \delta_{f}, \lambda_{m}, \lambda_{f}\right\}$. Figure 3 (a) shows the marginal distributions of the preference and production parameters. According to Figure 3 (a), the distribution of husbands' leisure preferences and the distribution of wives' leisure preference are similar. The husbands' production parameter distribution is more left skewed than wivies', indicating that the home production technology of males is estimated to be less efficient that of females.

Figure 3 (b) plots the bivariate distribution of spousal preference and production parameters. We see that there is a strong relationship between both the preference $\left(\lambda_{1}\right.$ and $\left.\lambda_{2}\right)$ and the production parameters $\left(\delta_{1}\right.$ and $\left.\delta_{2}\right)$ over the most of the support of the distribution. That is, husbands and wives exhibit a substantial degree of positive assortative matching with respect to both preference and production, although the sorting by production parameter is less pronounced. For husbands, there is a weak positive correlation between the preference and production parameters as seen in Figure 3c. For wives (Figure 3d), there is little evidence of a systematic relationship between productivity and preference parameters. Although the sample used for our estimation is totally different from that used in Del Boca and Flinn (2012), the distributions of unobserved preference and production parameters are reasonably similar. 


\subsection{Goodness of model fit}

The goodness of model fit is shown in figures 4,5 and 6. Figure 4 shows the labor participation rate conditional on education levels and conditional on ranges of values of the first and second principal components. The labor force participation rate for college-educated workers is higher than that of high school workers, which is correctly predicted by our model simulations. The model also replicates the pattern that the participation rates of males and females are both increasing in their first principal component. With regard to the second principal component, there is no relationship with the participation rate.

Figure 5 reports working hours (for those who work) conditional on the same variables. Our model replicates the pattern of working hours for high-school educated and college-educated females quite well. In general, college-educated females work more hours than high school educated females. The difference in working hours between high-school and college educated males is less significant. The model slightly under-predicts the number of working hours for high-school educated males and overpredicts hours for college-educated males. The model also correctly captures the pattern that male working hours are increasing (lowest for lowest value) in the first principal component and decreasing (highest for lowest value value) in the second principal component. On the other hand, female working hours do not exhibit any monotonic pattern with the principal components.

Figure 6 reports the conditional moments for housework hours. The model predicts that high-school household partners do more housework than college educated household partners, as seen in the data. However, the housework hours of high-school females are slightly under-predicted and the housework hours of college females are slightly over-predicted. With regard to the second principal component(associated with lower values of openness to experience), the model replicates the inverse $U$ shape (highest for middle value) for men and the decreasing pattern (higher for lower value) for women. There is no clear pattern of housework time with respect to the first principal component.

\subsection{External Validation}

In this section, we use the "fair share" question as a way of checking the validity of the model's implications. If the model is correctly specified and the "fair share" question is informative, individuals who report "I do much more than my fair share" should be observed to do more housework then their "fair share," and vice verse. To determine a fair share reference point, we simulate the housework time allocation under a Pareto weight equal to 0.501, which is the mean Pareto weight of 
the sample. Table 8 reports the housework hours and Pareto weight for both spouses categorized by "fair share" question. The column "Relative difference" reports the difference between the actual housework hours and the simulated housework hours under the Pareto weight set equal to 0.501. When individuals report doing more than their "fair share", the actual housework hours are larger than the simulated hours, and vice versa.

\subsection{Wage decomposition}

We next do a series of wage decompositions to understand the importance of education and personality traits in explaining gender gaps in accepted and offered wages. In our first decomposition, we decompose the wage gap at the mean into the following five sources:

$\underbrace{\log \bar{w}_{m}-\log \bar{w}_{f}}_{\text {mean wage gap }}=\underbrace{\gamma_{0 m}-\gamma_{0 f}}_{\text {unexplained part }}+\underbrace{\left(\gamma_{1 m} \bar{\theta}_{m}-\gamma_{1 f} \bar{\theta}_{f}\right)}_{\text {explained by traits }}+\underbrace{\left(\gamma_{2 m} \bar{e}_{m}-\gamma_{2 f} \bar{e}_{f}\right)}_{\text {explained by education }}+\underbrace{\left(\gamma_{3 m} \bar{c}_{m}-\gamma_{3 f} \bar{c}_{f}\right)}_{\text {explained by cognition }}+\underbrace{\left(\bar{\epsilon}_{m}-\bar{\epsilon}_{f}\right)}_{\text {selection bias }}$

Table 9 shows the gender wage gap attributable to different sources. The gap in accepted wages is $13.93 \%$, while the gap in offered wages is $18.44 \%$. As was seen in Table 9, females receive a higher return from their educational attainment. Education narrows the offered wage gap by 13.70 percentage points and the accepted wage gap by 14.00 percentage points. However, the female's advantage in the return to education is largely offset by a relative disadvantage in the return to personality traits. Conscientiousness and emotional stability are the most important two traits contributing to widening the wage gap (22.06 percentage points and 9.65 percentage points of offered wage gap). Openness to experience, on the other hand, narrows the gender wage gap 11.27 percentage points. We do not find any significant impact of agreeableness and extraversion in explaining the wage gap. In total, personality traits explain 20.46 percentage points of the offered wage gap. Their contribution to explaining the gender wage gap is even larger than the contribution from education. Cognitive ability explains only a small fraction of the wage gap.

Figure 7 plots the distributions of both offered wages and accepted wages. Female workers are on average more selective than male workers; that is, a lower fraction of females $(87 \%)$ accepts the offered wage and works in the labor market. Male workers' accepted wages are on average 1.70 percentage points higher than offered wages, whereas female workers accepted wages are on average 5.73 percentage points higher than offered wages. Thus the gender gap in accepted wages is smaller than the gap in offered wages. 
Table 9 showed that personality traits and education levels are both important to explaining gender wage gaps. Wage gaps can arise either because women have on average different traits and/or because women receive different payoffs in the labor market for their traits, as was evident in Table 6. We next explore whether and to what extent the gender gap is explained by differences in observed traits or differences in the market valuation of those traits. Following Oaxaca (1973) and Blinder (1973), we perform the following decomposition:

$$
\gamma_{1 m} \bar{\theta}_{m}-\gamma_{1 f} \bar{\theta}_{f}=\underbrace{\gamma_{1 m}\left(\bar{\theta}_{m}-\bar{\theta}_{f}\right)}_{\text {personality difference }}+\underbrace{\left(\gamma_{1 m}-\gamma_{1 f}\right) \bar{\theta}_{f}}_{\text {coefficient difference }}
$$

The first term is interpreted as the part of the wage differential due to differences in traits, and the second term is the difference arising from gender differences in the estimated coefficients associated with those traits. The decomposition results are reported in table 10 .

In general, the power of both personality traits and education in explaining wage gaps mostly stems from gender differences in labor market valuations. The differences in the values of personality traits explain 4.03 percentage points of the offered wage gap, whereas the differences in trait premia/penalties explain 14.30 percentage points. For example, male wage offers are significantly increased by high levels of conscientiousness and emotional stability; female wage offers are not significantly affected by either of the same traits. This gender difference in the valuation of conscientiousness widens the offered wage difference by 21.51 percentage points, which is the most important single factor explaining the gender wage gap. Meanwhile, the difference in the premium for emotional stability widens the offered wage difference by 9.65 percentage points. On the other hand, the gender difference in the valuation of openness to experience shrinks the gender wage gap by 11.08 percentage points. The contributions of other two traits- agreeableness and extraversion- are minor.

\section{Counterfactual experiments}

\subsection{Compare different forms of interactions between spouses}

We next examine how household behaviors differ in the cooperative and noncooperative regimes, by simulating behaviors that would result if all households interacted in a cooperative or noncooperative manner. We compare the time allocations and outcomes to our baseline model, where we found that roughly $40 \%$ of the households choose to cooperate. As seen in Table 11, under the cooperative regime, both men 
and women supply more hours to market work and to household work than in the baseline case. The working hours for men and women increase on average by 5.7 hours and 7.3 hours while the housework hours increase by 4.3 hours and 4.6 hours. The gap in accepted wages increases from $12.6 \%$ in the baseline model to $13.6 \%$ in the cooperative regime. Under the noncooperative regime, both men and women supply fewer hours to the labor market and to household work and devote more hours to leisure. Conversely the accepted wage gap is largest under cooperative regimes among the three cases, the average utility levels for both men and women under this regime are also the highest among three cases. This indicates that shrinking the observed gender wage gap is not necessarily welfare improving.

The explanation for the different time allocations under different regimes is intuitive. Define $M R S_{l K}^{m}\left(\Psi_{E}\right)=\frac{\frac{\partial V_{m}\left(\Psi_{E}\right)}{\partial l_{m}\left(\Psi_{E}\right)}}{\frac{\partial V_{m}\left(\Psi_{E}\right)}{\partial K\left(\Psi_{E}\right)}}$ as the marginal rate of substitution between private good (leisure $l$ ) and public good (home production $K$ ) under the regime $\Psi_{E}$. Its value equals to $\operatorname{MRS}_{l k}^{m}(P W(\alpha))=\frac{\left(1-\lambda_{m}\right)+\frac{1-\alpha}{\alpha}\left(1-\lambda_{f}\right)}{\lambda_{m}}$ under cooperative regime and equals to $M R S_{l k}^{m}(N E)=\frac{\left(1-\lambda_{m}\right)}{\lambda_{m}}$ under the non-cooperative regime. As a result, both $M R S_{l k}^{m}(P W(\alpha))>M R S_{l k}^{m}(N E)$ and $M R S_{l k}^{f}(P W(\alpha))>M R S_{l k}^{f}(N E)$ hold $\forall \alpha \in(0,1)$. In other words the public good $K$ is less attractive due to the less utility households get in the non-cooperative regime. Both spouses spend less time on producing the public good $\mathrm{K}$ but more time on the private good (leisure, $l$ ) in the non-cooperative regime. According to the household production technology $K=\tau_{m}^{\delta_{m}} \tau_{f}^{\delta_{f}} M^{1-\delta_{m}-\delta_{f}}$, less public good $K$ means less participation on the labor market and less time spent on housework, because producing $\mathrm{K}$ requires both monetary and time investments.

\subsection{The effect of positive assortative matching on the gender wage gap}

According to Figure 1 and Figure 3(b), married couples display positive assortative matching on both unobserved preference and production parameters as well as observed personality traits and cognitive abilities. We next consider how assortative matching of husbands and wives affects the gender wage gap. The baseline is simulated based on the structural model parameter estimates. Under the counterfactual experiment, we randomly assign males and females from the original sample to form new households. We call this experiment "random matching".

Table 12 suggests that eliminating the positive assortative matching between spouses generates small but significant effects on labor force participation rates and 
wage gaps. The labor participation rate of males and females decreases by 7.1 and 9.8 percentage points, and the accepted wage increases by $\mathrm{AU} \$ 0.7$ and $\mathrm{AU} \$ 1.1$. As a result, the gender gap in accepted wage shrinks from $12.5 \%$ in the baseline case to $10.3 \%$ in the random matching case. The driving force of this change is the decrease in the fraction of cooperative households. The reason is that extreme Pareto weights are now easier to generate when matching is random, resulting in a lower fraction of cooperative households. When households adopt noncooperative behaviors, they get less utility from the public good. Consequently, they offer less working hours to generate less public goods, and thus labor force participation rates also fall, especially for females.

\subsection{Equalizing pay opportunities}

Lastly, we use our model to simulate household time allocations and wage outcomes that would result if women were paid according to the male wage offer equation. That is, women may still receive different wage offers from men because their personal attributes differ, but their education, personality traits, and cognitive skill are valued in the same way in the labor market as for men.

As seen in Table 13, when men and women have the same wage offer equation, then women have better opportunities in the labor market on average. Women choose to spend more hours and men fewer hours doing market work. In terms of housework, women decrease their housework hours relative to the baseline and men increase their housework hours. Interestingly, when women receive the same wage offer equation as men, then the accepted wages for women are on average higher than the wages for men. The gender wage gap in accepted wage shapely changes from $12.6 \%$ in baseline model to $-8.3 \%$ in this "equal pay opportunities" simulation.

Figure 8 displays the distributions of offered wages and accepted wages in both the baseline and the counterfactual models. In the baseline model, the female's wage distribution is more left-skewed than male's wage distribution, indicating that the offered wages and accepted wages are lower for women than for men. However, this gap is totally eliminated and even reversed under "equal pay opportunities." The wage distribution for female workers exhibits more right-skewness and is more dispersed than the wage distribution of males.

\section{Conclusions}

In this paper, we studied the role of personality traits in household decisionmaking, specifically with regard to decisions about time allocation to housework and 
market work and the implications for gender wage disparities. First, we find that personality traits are significant determinants of household bargaining weights. The most crucial traits are emotional stability and agreeableness for both spouses. Second, we find that personality traits are also important determinants of offered wages and that their combined influence compares to the effect of education on wages. Men's and women's personality traits are valued differently in the labor market, with men receiving wage premiums for conscientiousness and stability and women receiving a premium for openness to experience. Both men and women are penalized in terms of wages for being more agreeable. Men and women receive similar returns to a year of education (around 5\%) but men receive a higher premium for cognitive ability than women. Third, an analysis of accepted wages without controlling for selective labor market participation tends to understate the contribution of personality traits to wages. Fourth, an Oaxaca-Blinder type decomposition analysis shows that the gender wage gap largely is attributable to gender differences in market valuations of traits rather than to differences in the levels of those traits. Simulation results show that if women would have the same wage offer equation as men, women would work about five hours more per week and the accepted wage gap would be reversed, with women having $8.3 \%$ higher wages.

The model we have estimated allows households to choose to behave cooperatively or noncooperatively, with personality attributes potentially affecting household bargaining parameters. We find that $37.5 \%$ of households behave cooperatively. Cooperation leads a household to assign a higher value to public goods that require both monetary and time investments to produce. This leads both men and women to supply a greater number of hours to the labor market and to housework than they would under a noncooperative regime. Observed wage gaps are higher under a cooperative regime, but utility values of both males and females are also highest.

We also document positive assortative matching of men and women with regard to education and personality traits. The assortative matching tends to lead to higher levels of cooperation than would be observed under random matching of personality types. Simulation results show that eliminating the positive sorting decreases the gender gap of accepted wage from $12.6 \%$ to $10.3 \%$, largely because of the reduction of the cooperative fraction of households.

There are several ways that our analysis could be extended in future work. First, we focused on individuals age 30-50 who do not have children under the age of 14 living in their home, but children and their effects on housework and labor supply decisions could be explicitly incorporated in the model. Second, our model viewed the household decision as a static decision at each age, but it could be extended to an explicit dynamic life-cycle framework. 


\section{References}

Altonji, J. G. and Blank, R. M. (1999). Race and gender in the labor market. Handbook of labor economics, 3:3143-3259.

Autor, D. H., Katz, L. F., and Kearney, M. S. (2008). Trends in us wage inequality: Revising the revisionists. The Review of economics and statistics, 90(2):300-323.

Becker, G. S. (1981). A Treatise on the Family. Harvard university press.

Blau, F. D. and Kahn, L. M. (1997). Swimming upstream: Trends in the gender wage differential in the 1980s. Journal of labor Economics, pages 1-42.

Blau, F. D. and Kahn, L. M. (2006). The us gender pay gap in the 1990s: Slowing convergence. Industrial \& Labor Relations Review, 60(1):45-66.

Blinder, A. S. (1973). Wage discrimination: reduced form and structural estimates. Journal of Human resources, pages 436-455.

Borghans, L., Duckworth, A. L., Heckman, J. J., and Ter Weel, B. (2008). The economics and psychology of personality traits. Journal of human Resources, 43(4):972-1059.

Bourguignon, F. (1984). Rationalité individuelle ou rationalité stratégique: le cas de l'offre familiale de travail. Revue économique, pages 147-162.

Braakmann, N. (2009). The role of psychological traits for the gender gap in full-time employment and wages: Evidence from germany. SOEP Paper, (162).

Cattan, S. (2013). Psychological traits and the gender wage gap. The Institute for Fiscal Studies.

Chiappori, P.-A. (1988). Rational household labor supply. Econometrica: Journal of the Econometric Society, pages 63-90.

Croson, R. and Gneezy, U. (2009). Gender differences in preferences. Journal of Economic literature, 47(2):448-474. 
Cubel, M., Nuevo-Chiquero, A., Sanchez-Pages, S., and Vidal-Fernandez, M. (2016). Do personality traits affect productivity? evidence from the laboratory. The Economic Journal, 126(592):654-681.

Del Boca, D. and Flinn, C. (2012). Endogenous household interaction. Journal of Econometrics, 166(1):49-65.

Del Boca, D., Flinn, C., and Wiswall, M. (2014). Household choices and child development. The Review of Economic Studies, 81(1):137-185.

Del Boca, D. and Flinn, C. J. (1995). Rationalizing child-support decisions. The American Economic Review, pages 1241-1262.

Dupuy, A. and Galichon, A. (2014). Personality traits and the marriage market. Journal of Political Economy, 122(6):1271-1319.

Fletcher, J. M. (2013). The effects of personality traits on adult labor market outcomes: Evidence from siblings. Journal of Economic Behavior \& Organization, $89: 122-135$.

Gemici, A. (2011). Family migration and labor market outcomes. Manuscript, New York University.

Gemici, A. and Laufer, S. (2011). Marriage and cohabitation. New York University, mimeo.

Goldberg, L. R. (1992). The development of markers for the big-five factor structure. Psychological assessment, 4(1):26.

Heckman, J. J. and Raut, L. K. (2016). Intergenerational long-term effects of preschool-structural estimates from a discrete dynamic programming model. Journal of econometrics, 191(1):164-175.

Heckman, J. J., Stixrud, J., and Urzua, S. (2006). The effects of cognitive and noncognitive abilities on labor market outcomes and social behavior. Journal of Labor Economics, 24(3):411-482.

Heineck, G. (2011). Does it pay to be nice? personality and earnings in the united kingdom. Industrial \& Labor Relations Review, 64(5):1020-1038.

Heineck, G. and Anger, S. (2010). The returns to cognitive abilities and personality traits in germany. Labour Economics, 17(3):535-546. 
Joubert, C. and Todd, P. (2016). Expanding pension coverage: A dynamic analysis of chile's pension reform. Technical report, unpublished manuscript.

Losoncz, I. (2009). Personality traits in hilda1. Australian Social Policy No. 8, page 169.

Lundberg, S. (2012). Personality and marital surplus. IZA Journal of Labor Economics, 1(1):1.

Lundberg, S. and Pollak, R. A. (1993). Separate spheres bargaining and the marriage market. Journal of political Economy, pages 988-1010.

Manser, M. and Brown, M. (1980). Marriage and household decision-making: A bargaining analysis. International economic review, pages 31-44.

Marianne, B. (2011). New perspectives on gender. Handbook of labor economics, 4:1543-1590.

McElroy, M. B. and Horney, M. J. (1981). Nash-bargained household decisions: Toward a generalization of the theory of demand. International economic review, pages 333-349.

Mueller, G. and Plug, E. (2006). Estimating the effect of personality on male and female earnings. Industrial \& Labor Relations Review, 60(1):3-22.

Nyhus, E. K. and Pons, E. (2005). The effects of personality on earnings. Journal of Economic Psychology, 26(3):363-384.

Oaxaca, R. (1973). Male-female wage differentials in urban labor markets. International economic review, pages 693-709.

Saucier, G. (1994). Mini-markers: A brief version of goldberg's unipolar big-five markers. Journal of personality assessment, 63(3):506-516.

Summerfield, M., Freidin, S., Hahn, M., Li, N., Macalalad, N., Mundy, L., Watson, N., Wilkins, R., and Wooden, M. (2015). Hilda user manual-release 14.

Tartari, M. (2015). Divorce and the cognitive achievement of children. International Economic Review, 56(2):597-645.

Terracciano, A., Costa, P. T., and McCrae, R. R. (2006). Personality plasticity after age 30. Personality and Social Psychology Bulletin, 32(8):999-1009. 
Terracciano, A., McCrae, R. R., and Costa, P. T. (2010). Intra-individual change in personality stability and age. Journal of Research in Personality, 44(1):31-37.

Wooden, M. (2013). The measurement of cognitive ability in wave 12 of the hilda survey. 


\section{Tables}

Table 1: Personality traits questionnaire

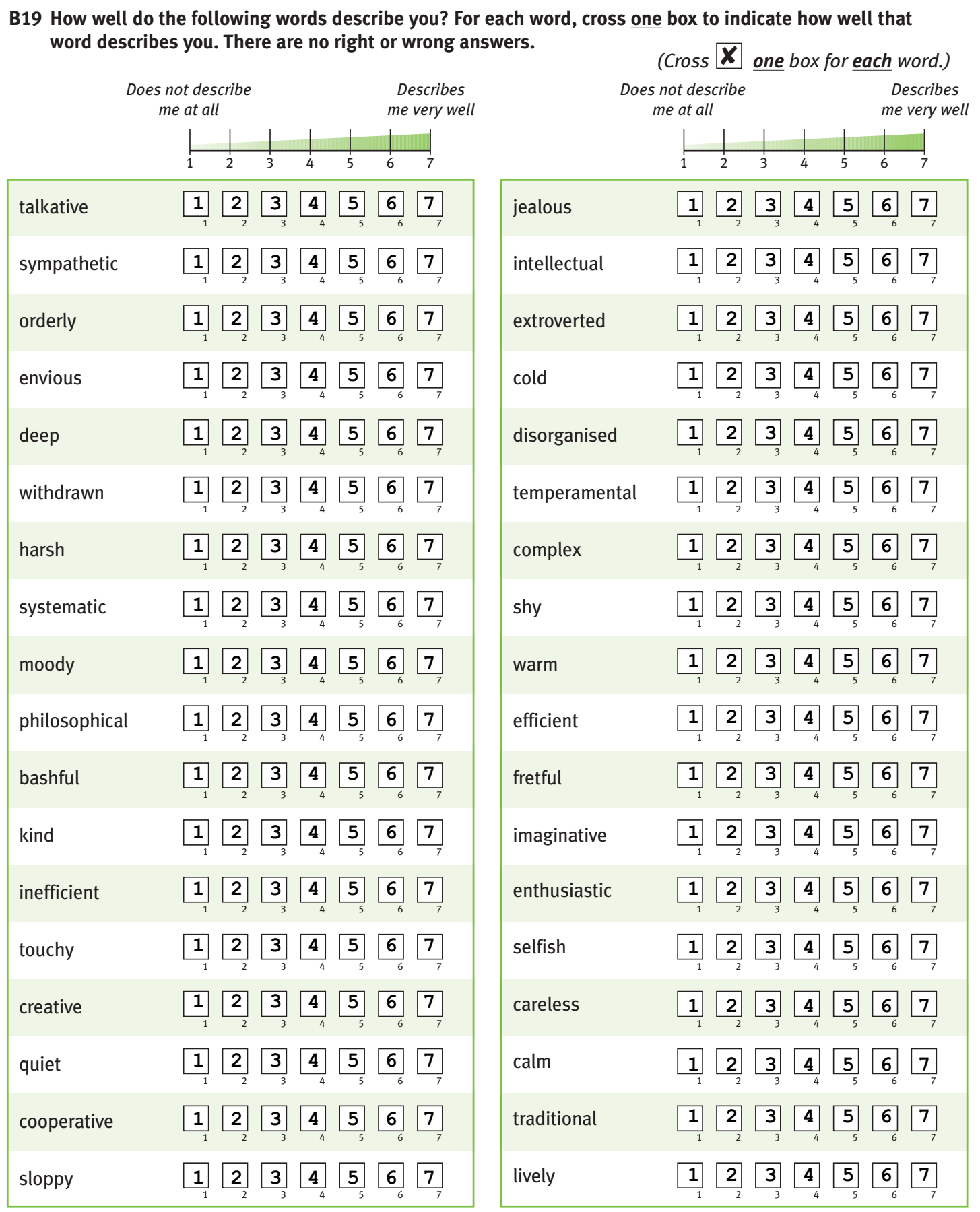


Table 2: Key variables in HILDA, means and (standard errors)

\begin{tabular}{|c|c|c|c|c|}
\hline Variable & Male & Obs. & Female & Obs. \\
\hline Age & $\begin{array}{l}39.79 \\
(6.36)\end{array}$ & 973 & $\begin{array}{l}37.90 \\
(7.87)\end{array}$ & 973 \\
\hline Employment & $\begin{array}{c}.95 \\
(.24)\end{array}$ & 973 & $\begin{array}{c}.87 \\
(.34)\end{array}$ & 973 \\
\hline Hourly Wage & $\begin{array}{c}29.06 \\
(15.99)\end{array}$ & 816 & $\begin{array}{c}25.33 \\
(14.63)\end{array}$ & 805 \\
\hline Working hours & $\begin{array}{l}43.99 \\
(9.70)\end{array}$ & 913 & $\begin{array}{c}36.29 \\
(13.14)\end{array}$ & 848 \\
\hline Housework & $\begin{array}{c}15.39 \\
(11.15)\end{array}$ & 973 & $\begin{array}{c}20.91 \\
(13.89)\end{array}$ & 973 \\
\hline Education & $\begin{array}{l}13.13 \\
(2.35)\end{array}$ & 973 & $\begin{array}{l}13.37 \\
(2.44)\end{array}$ & 973 \\
\hline Other Income & $\begin{array}{c}312.87 \\
(252.12)\end{array}$ & 973 & $\begin{array}{l}- \\
-\end{array}$ & - \\
\hline \multicolumn{5}{|c|}{ Personality traits and cognitive ability } \\
\hline Cognition & $\begin{array}{c}0.12 \\
(0.70)\end{array}$ & 973 & $\begin{array}{c}0.23 \\
(0.66)\end{array}$ & 973 \\
\hline Openness & $\begin{array}{c}4.33 \\
(0.96)\end{array}$ & 973 & $\begin{array}{c}4.28 \\
(0.99)\end{array}$ & 973 \\
\hline Conscientiousness & $\begin{array}{c}5.11 \\
(0.94)\end{array}$ & 973 & $\begin{array}{c}5.38 \\
(0.97)\end{array}$ & 973 \\
\hline Extraversion & $\begin{array}{c}4.30 \\
(1.00)\end{array}$ & 973 & $\begin{array}{c}4.66 \\
(1.00)\end{array}$ & 973 \\
\hline Agreeableness & $\begin{array}{c}5.20 \\
(0.84)\end{array}$ & 1316 & $\begin{array}{c}5.72 \\
(0.76)\end{array}$ & 1316 \\
\hline Stability & $\begin{array}{c}5.12 \\
(1.01)\end{array}$ & 973 & $\begin{array}{c}5.14 \\
(1.00)\end{array}$ & 973 \\
\hline
\end{tabular}

1. Both employment and hourly wage are conditional on being employed.

2. The other income is the pooled household income other than labor earnings. 
Table 3: The Effects of Personality on Earnings and Labor Market Participation

\begin{tabular}{ccccc}
\hline & \multicolumn{2}{c}{ Log Hourly Earning } & \multicolumn{2}{c}{ Labor Market Participation } \\
\hline & Males & Females & Males & Females \\
\hline Openness & -0.017 & -0.016 & -0.020 & -0.013 \\
& $(0.020)$ & $(0.018)$ & $(0.009)$ & $(0.011)$ \\
Conscientiousness & $0.044^{*}$ & 0.016 & 0.009 & $0.025^{*}$ \\
& $(0.019)$ & $(0.019)$ & $(0.009)$ & $(0.012)$ \\
Extraversion & 0.013 & 0.032 & -0.004 & -0.003 \\
& $(0.018)$ & $(0.017)$ & $(0.008)$ & $(0.009)$ \\
Agreeableness & -0.001 & -0.012 & -0.006 & 0.014 \\
& $(0.022)$ & $(0.023)$ & $(0.010)$ & $(0.015)$ \\
Stability & -0.018 & -0.005 & 0.001 & -0.004 \\
& $(0.020)$ & $(0.019)$ & $(0.009)$ & $(0.012)$ \\
Education & $0.052^{* * *}$ & $0.058^{* * *}$ & $0.009 *$ & $0.020 * * *$ \\
& $(0.008)$ & $(0.007)$ & $(0.004)$ & $(0.005)$ \\
Cognition & $0.121^{* * *}$ & $0.024^{* *}$ & $0.047^{* * *}$ & $0.073^{* * *}$ \\
& $(0.029)$ & $(0.029)$ & $(0.013)$ & $(0.020)$ \\
Age & 0.022 & 0.037 & 0.000 & 0.023 \\
& $(0.022)$ & $(0.041)$ & $(0.012)$ & $(0.028)$ \\
Age $/ 100$ & -0.037 & -0.066 & -0.001 & -0.027 \\
& $(0.029)$ & $(0.052)$ & $(0.015)$ & $(0.035)$
\end{tabular}

Notes:Robust standard errors are reported in parentheses.

* Statistically significant at the .05 level; ${ }^{* *}$ at the .01 level; ${ }^{* * *}$ at the .001 level.

Table 4: Responses to the "fair share" question

\begin{tabular}{ccc}
\hline Percentage(\%) & Male & Female \\
\hline Much More(1) & 1.85 & 16.62 \\
A bit More(2) & 13.14 & 36.31 \\
Fair Share(3) & 58.62 & 39.90 \\
A bit Less(4) & 23.61 & 6.46 \\
Much Less(5) & 2.77 & 0.72 \\
\hline Correlation & \multicolumn{2}{c}{-0.4229} \\
\hline
\end{tabular}


Table 5: Principal-components analysis for five dimensional personality traits

\begin{tabular}{c|cc|cc}
\hline & \multicolumn{2}{|c|}{ Male } & \multicolumn{2}{c}{ Female } \\
& 1 & 2 & 1 & 2 \\
\hline Eigenvalues & 1.47 & 1.22 & 1.59 & 1.18 \\
Variance & $29.4 \%$ & $24.5 \%$ & $31.8 \%$ & $23.5 \%$ \\
Openness to experience & 0.144 & 0.771 & 0.087 & 0.820 \\
Conscientiousness & 0.556 & -0.086 & 0.511 & -0.066 \\
Extraversion & 0.363 & -0.168 & 0.466 & -0.009 \\
Agreeableness & 0.543 & 0.407 & 0.456 & 0.408 \\
Emotional stability & 0.493 & -0.452 & 0.553 & -0.397 \\
\hline
\end{tabular}


Table 6: Parameter estimates

\begin{tabular}{|c|c|c|c|c|c|}
\hline \multirow[t]{2}{*}{ Part 1} & \multicolumn{2}{|c|}{ Male } & & \multicolumn{2}{|c|}{ Female } \\
\hline & Estimates & S.E. & & Estimates & S.E. \\
\hline \multicolumn{6}{|c|}{ Log wage equation } \\
\hline$\gamma_{0 m}$ & 2.1822 & $\overline{(0.1003)}$ & $\overline{\gamma_{0 f}}$ & 2.1028 & $(0.0900)$ \\
\hline$\gamma_{1 m}(O p n)$ & -0.0157 & $(0.0057)$ & $\gamma_{1 f}(O p n)$ & 0.0102 & $(0.0052)$ \\
\hline$\gamma_{1 m}(C o s)$ & 0.0535 & $(0.0061)$ & $\gamma_{1 f}(C o s)$ & 0.0098 & $(0.0052)$ \\
\hline$\gamma_{1 m}(E x t)$ & 0.0120 & $(0.0103)$ & $\gamma_{1 f}(E x t)$ & 0.0068 & $(0.0085)$ \\
\hline$\gamma_{1 m}(A g r)$ & -0.0045 & $(0.0040)$ & $\gamma_{1 f}(A g r)$ & -0.0047 & $(0.0016)$ \\
\hline$\gamma_{1 m}(S t b)$ & 0.0184 & $(0.0057)$ & $\gamma_{1 f}(S t b)$ & -0.0004 & $(0.0012)$ \\
\hline$\gamma_{2 m}(E d u)$ & 0.0554 & $(0.0090)$ & $\gamma_{2 f}(E d u)$ & 0.0646 & $(0.0058)$ \\
\hline$\gamma_{3 f}(\operatorname{Cog})$ & 0.1155 & $(0.0232)$ & $\gamma_{3 f}(\mathrm{Cog})$ & 0.0225 & $(0.0057)$ \\
\hline$\sigma\left(\epsilon_{m}\right)$ & 0.6314 & $(0.1025)$ & $\sigma\left(\epsilon_{f}\right)$ & 0.9153 & $(0.2243)$ \\
\hline$\rho$ & 0.6756 & $(0.3391)$ & & & \\
\hline \multicolumn{6}{|c|}{ Pareto Weight } \\
\hline$\gamma_{4 m}-\gamma_{4 f}$ & -0.2106 & $(0.1033)$ & & & \\
\hline$\gamma_{5 m}(O p n)$ & -0.1335 & $(0.0328)$ & $\gamma_{5 f}(O p n)$ & -0.2264 & $(0.0242)$ \\
\hline$\gamma_{5 m}(\mathrm{Cos})$ & -0.1228 & $(0.0443)$ & $\gamma_{5 f}(C o s)$ & -0.0206 & $(0.0270)$ \\
\hline$\gamma_{5 m}(E x t)$ & -0.1306 & $(0.0208)$ & $\gamma_{5 f}(E x t)$ & -0.1374 & $(0.0273)$ \\
\hline$\gamma_{5 m}(A g r)$ & -0.2151 & $(0.0707)$ & $\gamma_{5 f}(A g r)$ & -0.1062 & $(0.0228)$ \\
\hline$\gamma_{5 m}(S t b)$ & -0.2016 & $(0.0582)$ & $\gamma_{5 f}(S t b)$ & -0.3252 & $(0.0373)$ \\
\hline$\gamma_{6 m}(E d u)$ & 0.0405 & $(0.0122)$ & $\gamma_{6 f}(E d u)$ & -0.0144 & $(0.0057)$ \\
\hline$\gamma_{7 m}(\operatorname{Cog})$ & 0.5018 & $(0.0978)$ & $\gamma_{7 f}(\operatorname{Cog})$ & 0.4580 & $(0.1632)$ \\
\hline$\gamma_{7 m}($ Age $)$ & -0.0064 & $(0.0406)$ & $\gamma_{7 f}($ Age $)$ & 0.1036 & $(0.0286)$ \\
\hline Part 2 & \multicolumn{5}{|c|}{ Preference and Production Parameters } \\
\hline \multicolumn{3}{|c|}{$\operatorname{Mean}(\mu)$} & \multicolumn{2}{|c|}{ Co-variance $\left(\sum\right)$} & \\
\hline$\lambda_{m}$ & 0.5288 & 0.5263 & 0.9362 & -0.4269 & -0.6833 \\
\hline S.E. & $(0.0248)$ & $(0.0639)$ & $(0.2181)$ & $(0.2237)$ & $(0.1620)$ \\
\hline$\lambda_{f}$ & 0.5748 & 0.9362 & 1.8839 & -0.8790 & -1.0070 \\
\hline S.E. & $(0.0639)$ & $(0.2181)$ & $(0.7020)$ & $(0.4386)$ & $(0.3849)$ \\
\hline$\delta_{m}$ & -1.8913 & -0.4269 & -0.8790 & 0.9875 & 1.5437 \\
\hline S.E. & $(0.0140)$ & $(0.2237)$ & $(0.4386)$ & $(0.3929)$ & $(0.4778)$ \\
\hline$\delta_{m}$ & -1.6856 & -0.6833 & -1.0070 & 1.5437 & 3.4712 \\
\hline S.E. & $(0.0692)$ & $(0.1620)$ & $(0.3849)$ & $(0.4778)$ & $(1.3606)$ \\
\hline
\end{tabular}


Table 7: The fraction of households playing cooperatively along with Pareto weight $\alpha$

\begin{tabular}{c|cc}
\hline$\alpha$ & Fraction & Obs. \\
\hline$[0.05,0.15)$ & 0 & 5 \\
{$[0.15,0.25)$} & 0.038 & 53 \\
{$[0.25,0.35)$} & 0.255 & 110 \\
{$[0.35,0.45)$} & 0.502 & 201 \\
{$[0.45,0.55)$} & 0.661 & 221 \\
{$[0.55,0.65)$} & 0.368 & 204 \\
{$[0.65,0.75)$} & 0.096 & 135 \\
{$[0.75,0.85)$} & 0 & 37 \\
{$[0.85,0.95]$} & 0 & 7 \\
\hline Total & 0.375 & 973
\end{tabular}

Note: all Pareto wights $\alpha$ are within range [0.05,0.95]. The mean and S.D. of $\alpha$ are 0.500 and 0.154.

Table 8: The average housework hours categorized by "fair share" question

\begin{tabular}{c|ccc|ccc}
\hline $\begin{array}{c}\text { Fair } \\
\text { share }\end{array}$ & $\begin{array}{c}\text { Housework } \\
\text { hours }\end{array}$ & $\begin{array}{c}\text { Relative } \\
\text { difference }\end{array}$ & $\begin{array}{c}\text { Number } \\
\text { of obs. }\end{array}$ & $\begin{array}{c}\text { Housework } \\
\text { hours }\end{array}$ & $\begin{array}{c}\text { Relative } \\
\text { difference }\end{array}$ & $\begin{array}{c}\text { Number } \\
\text { of obs. }\end{array}$ \\
\hline Much More(1) & 22.28 & 7.21 & 18 & 24.33 & 1.93 & 162 \\
A bit More(2) & 17.32 & 1.22 & 128 & 21.46 & -2.26 & 353 \\
Fair Share(3) & 15.66 & -1.60 & 569 & 19.63 & -3.22 & 388 \\
A bit Less(4) & 13.51 & -3.30 & 230 & 15.52 & -5.39 & 63 \\
Much Less(5) & 11.89 & -3.30 & 27 & 11.14 & -7.45 & 7 \\
\hline
\end{tabular}

Table 9: The decomposition of gender wage gap

\begin{tabular}{c|cc}
\hline & Offered Wage & Accepted Wage \\
\hline$\Delta \gamma_{0}$ & 0.0794 & 0.0794 \\
Education & -0.1370 & -0.1400 \\
Conscientiousness & 0.2206 & 0.2212 \\
Openness & -0.1127 & -0.1129 \\
Stability & 0.0965 & 0.0967 \\
Agreeableness & 0.0035 & 0.0035 \\
Extraversion & 0.0199 & 0.0199 \\
Cognitive & 0.0089 & 0.01117 \\
$\Delta \epsilon$ & 0 & -0.0403 \\
\hline Total & 0.1844 & 0.1393 \\
\hline
\end{tabular}


Table 10: The Oaxaca-Blinder decomposition for personality traits and educational attainments

\begin{tabular}{c|ccc}
\hline & $\begin{array}{c}\text { Total } \\
\text { difference }\end{array}$ & $\begin{array}{c}\text { Due to } \\
\text { characteristic }\end{array}$ & $\begin{array}{c}\text { Due to } \\
\text { coefficients }\end{array}$ \\
\hline Education & -0.1370 & -0.0132 & -0.1238 \\
Conscientiousness & 0.2206 & -0.0145 & 0.2351 \\
Openness & -0.1127 & -0.0019 & -0.1108 \\
Stability & 0.0965 & -0.0002 & 0.0967 \\
Agreeableness & 0.0035 & 0.0024 & 0.0011 \\
Extraversion & 0.0199 & -0.0038 & 0.0237 \\
Cognitive & 0.0089 & -0.0120 & 0.0210 \\
\hline Total & 0.0998 & -0.0403 & 0.1430 \\
\hline
\end{tabular}

Table 11: The new allocations under different forms of interactions

\begin{tabular}{c|ccccccc}
\hline & Gender & $\begin{array}{c}\text { Participation } \\
\text { rate }\end{array}$ & $\begin{array}{c}\text { Housework } \\
\text { hours }\end{array}$ & $\begin{array}{c}\text { Working } \\
\text { hours }\end{array}$ & $\begin{array}{c}\text { Accepted } \\
\text { wages }\end{array}$ & $\begin{array}{c}\text { Wage } \\
\text { Gap }\end{array}$ & Utility \\
\hline Baseline & Males & $93.0 \%$ & 15.2 & 44.1 & 28.9 & $12.6 \%$ & 5.58 \\
& Females & $86.5 \%$ & 20.9 & 36.3 & 25.7 & 5.62 \\
\hline Cooperative & Males & $96.6 \%$ & 19.5 & 49.8 & 28.5 & \multirow{2}{*}{$13.6 \%$} & 5.60 \\
& Females & $91.7 \%$ & 25.5 & 43.6 & 25.0 & 5.64 \\
\hline Non- & Males & $91.3 \%$ & 12.7 & 40.8 & 29.0 & \multirow{2}{*}{ (10.8\% } & 5.56 \\
cooperative & Females & $81.7 \%$ & 18.4 & 33.0 & 26.2 & & 5.60 \\
\hline
\end{tabular}

Table 12: The counterfactual experiment of random match

\begin{tabular}{c|ccccccc}
\hline & Gender & $\begin{array}{c}\text { Participation } \\
\text { rate }\end{array}$ & $\begin{array}{c}\text { Housework } \\
\text { hours }\end{array}$ & $\begin{array}{c}\text { Working } \\
\text { hours }\end{array}$ & $\begin{array}{c}\text { Accepted } \\
\text { wages }\end{array}$ & $\begin{array}{c}\text { Wage } \\
\text { Gap }\end{array}$ & $\begin{array}{c}\text { Cooperative } \\
\text { Fraction }\end{array}$ \\
\hline Baseline & Males & $93.0 \%$ & 15.2 & 44.1 & 28.9 & \multirow{2}{*}{$12.6 \%$} & $37.5 \%$ \\
& Females & $86.5 \%$ & 20.9 & 36.3 & 25.7 & & \\
\hline Random & Males & $85.9 \%$ & 15.1 & 43.5 & 29.6 & \multirow{2}{*}{$10.3 \%$} & $29.1 \%$ \\
mating & Females & $76.3 \%$ & 20.5 & 39.5 & 26.8 & & \\
\hline
\end{tabular}


Table 13: The new allocations under equal pay experiment

\begin{tabular}{c|ccccccc}
\hline & Gender & $\begin{array}{c}\text { Participation } \\
\text { rate }\end{array}$ & $\begin{array}{c}\text { Housework } \\
\text { hours }\end{array}$ & $\begin{array}{c}\text { Working } \\
\text { hours }\end{array}$ & $\begin{array}{c}\text { Accepted } \\
\text { wages }\end{array}$ & $\begin{array}{c}\text { Wage } \\
\text { Gap }\end{array}$ & $\begin{array}{c}\text { Cooperative } \\
\text { Fraction }\end{array}$ \\
\hline Baseline & Males & $93.0 \%$ & 15.2 & 44.1 & 28.9 & \multirow{2}{*}{$12.6 \%$} & \multirow{2}{*}{$37.5 \%$} \\
& Females & $86.5 \%$ & 20.9 & 36.3 & 25.7 & & \\
\hline Equal pay & Males & $88.4 \%$ & 16.1 & 41.2 & 28.8 & \multirow{2}{*}{$-8.6 \%$} & \multirow{2}{*}{$39.5 \%$} \\
& Females & $92.8 \%$ & 19.4 & 41.4 & 31.5 & & \\
\hline
\end{tabular}




\section{Figure Captions}

Figure 1. Assortative matching of personality traits and cognitive ability

Figure 2. The elasticity of $\Gamma_{k}(i)$ with respect to the Pareto weight

Figure 3. Spousal preference and production parameters

Figure 4. Goodness of model fit1: labor participation

Figure 5. Goodness of model fit 2: working hours

Figure 6. Goodness of model fit 3: housework hours

Figure 7. Distributions of accepted wages and offered wages

Figure 8. Distributions of accepted wages and offered wages 


\section{Figures}

Figure 1: Assortative matching of personality traits and cognitive ability
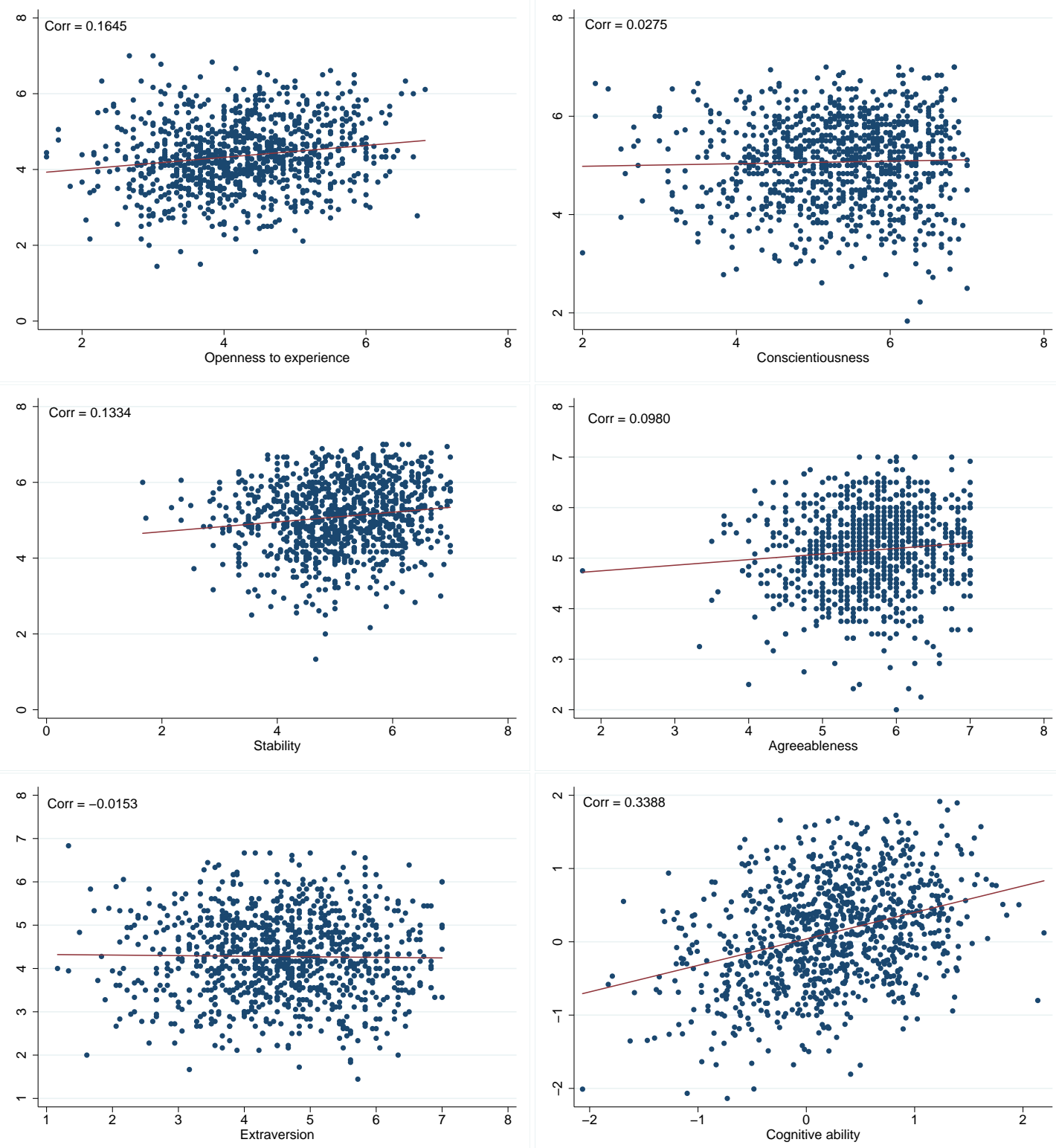
Figure 2: The elasticity of $\Gamma_{k}(i)$ with respect to the Pareto weight
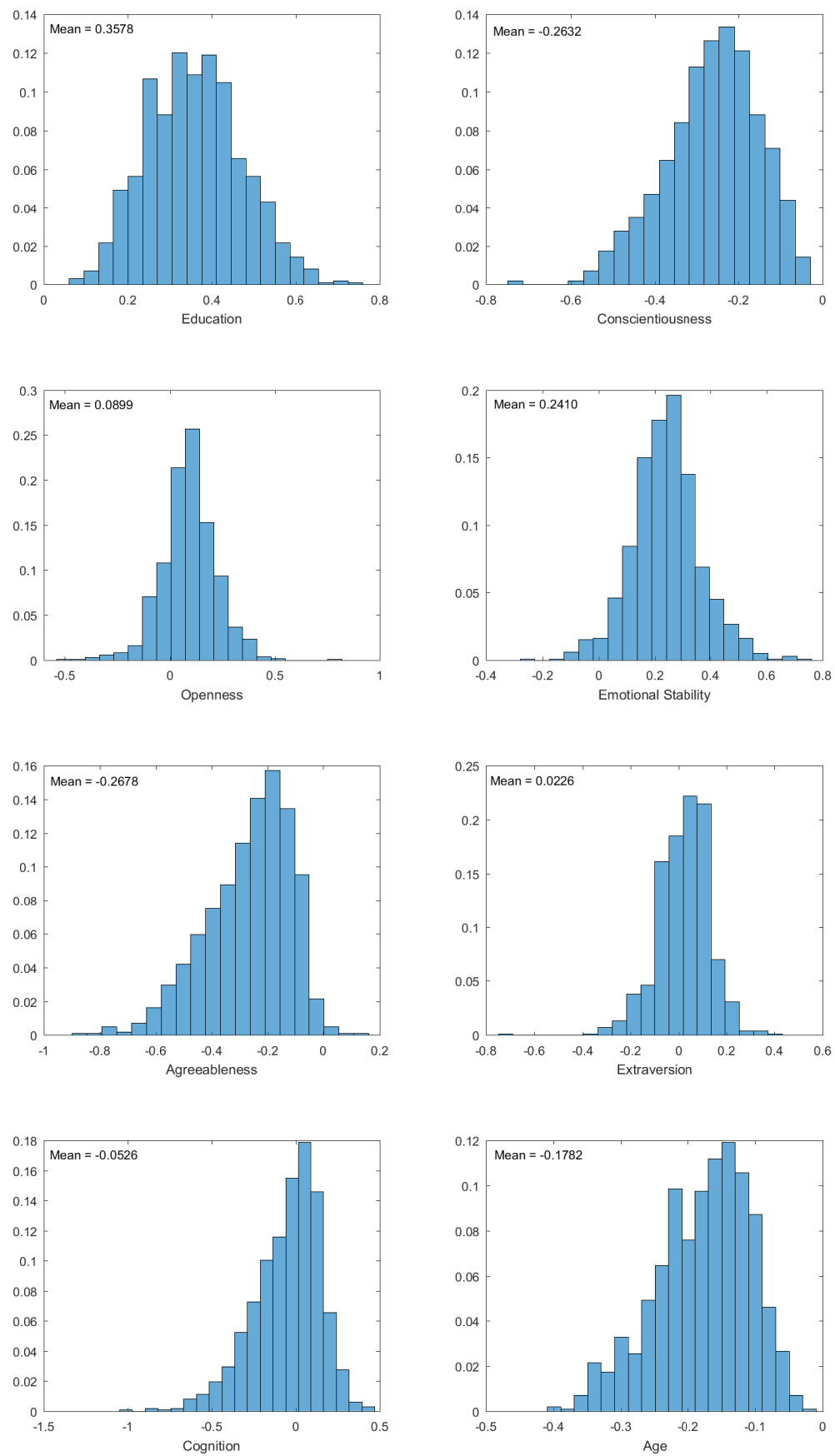
Figure 3: Spousal preference and production parameters

(a) Histograms of spousal production and preference parameters
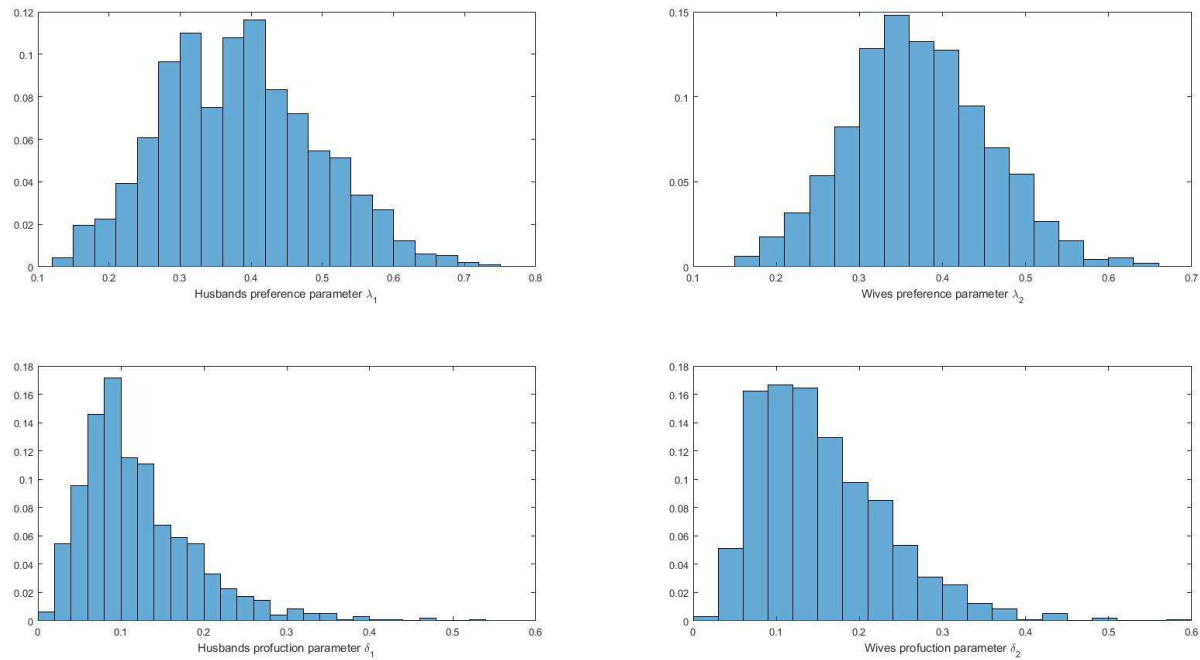

(b) bivariate relationships between production and preference parameters
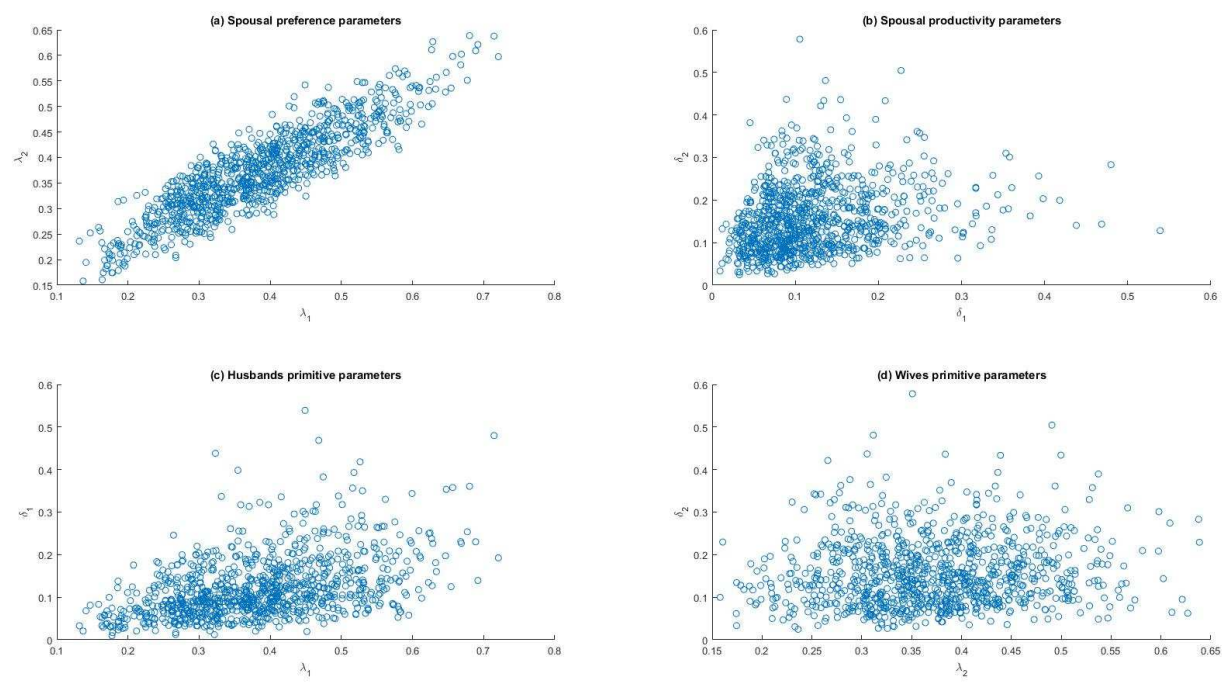
Figure 4: Goodness of model fit1: labor participation
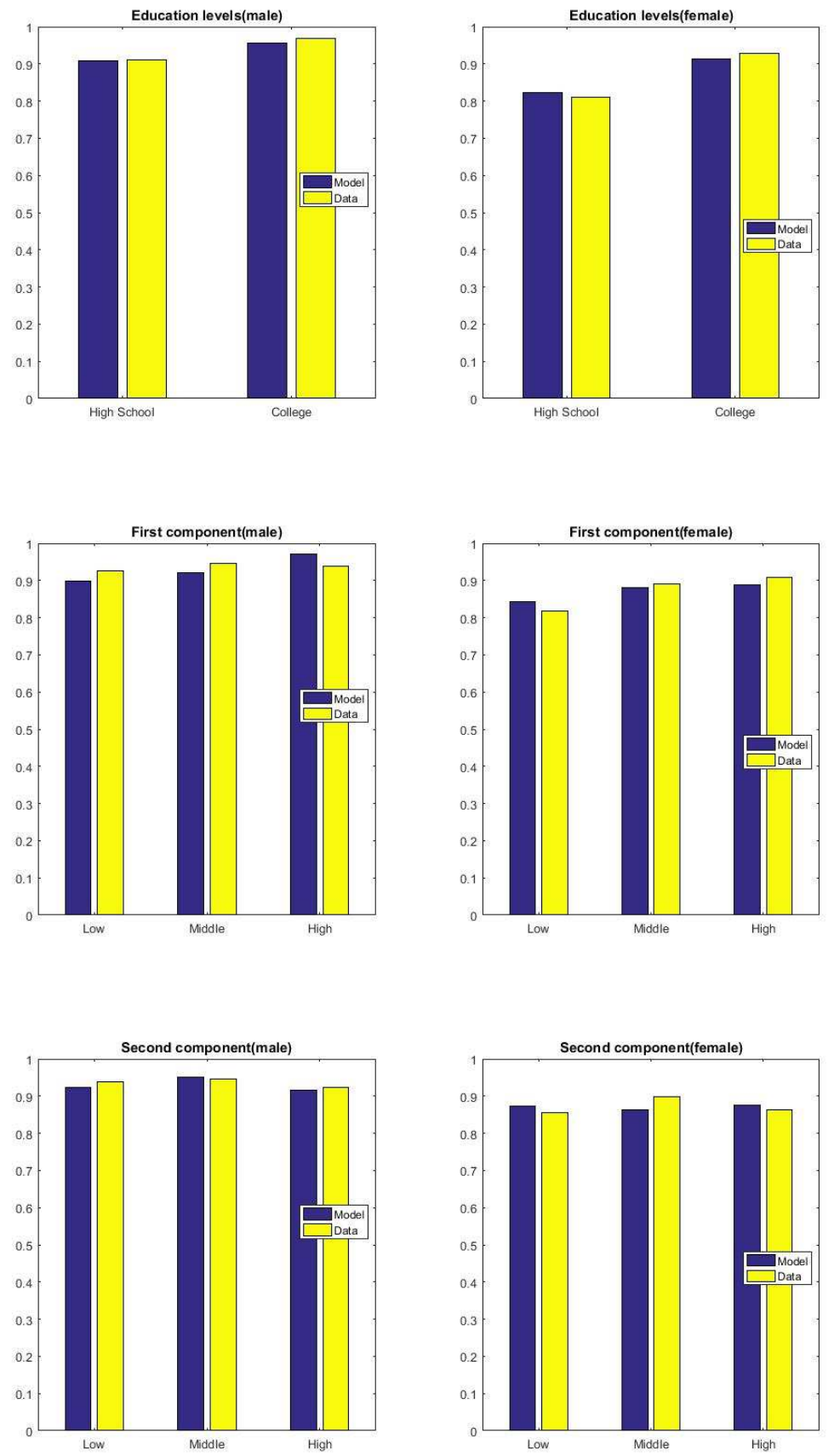
Figure 5: Goodness of model fit 2: working hours
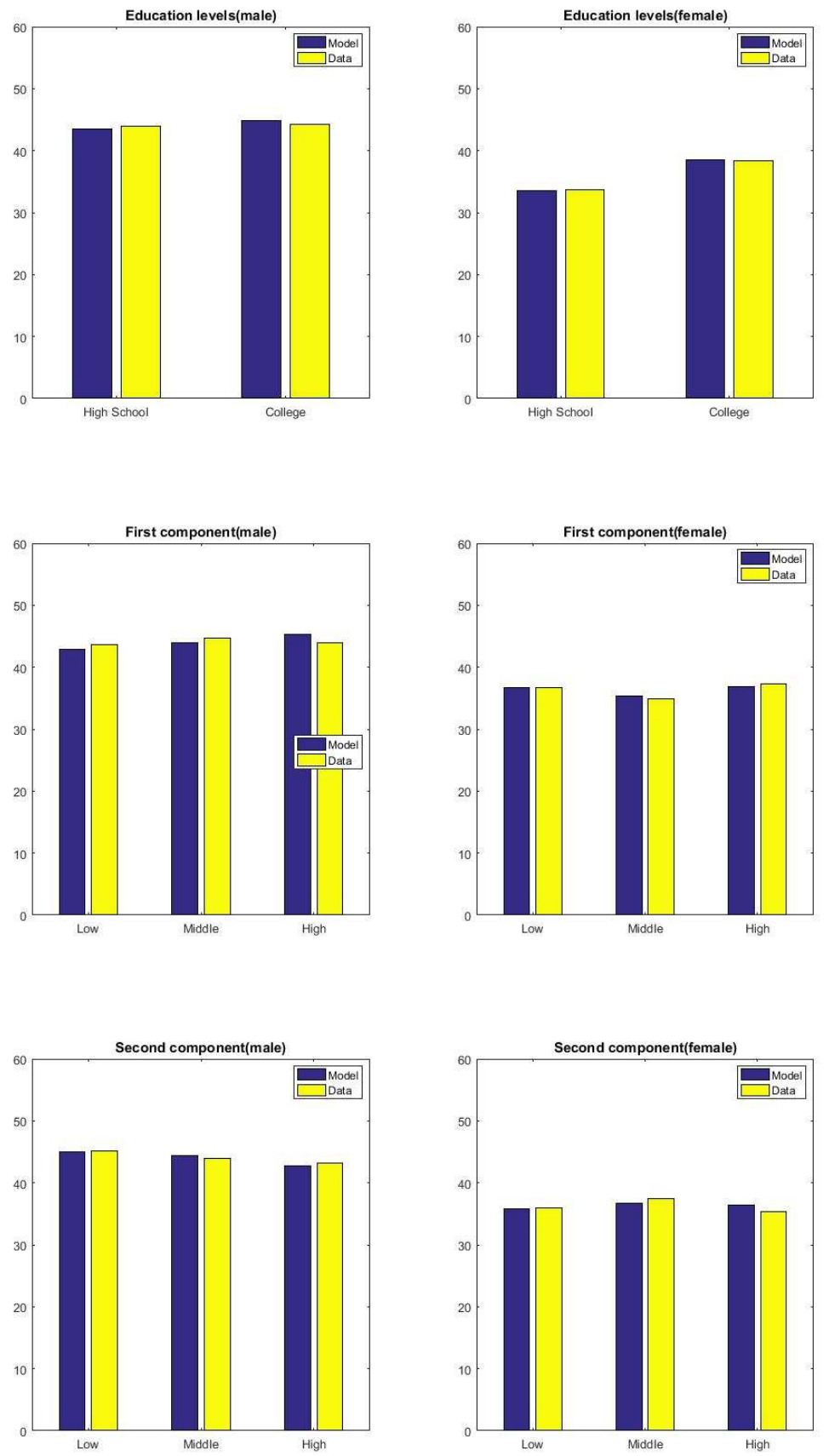
Figure 6: Goodness of model fit 3: housework hours
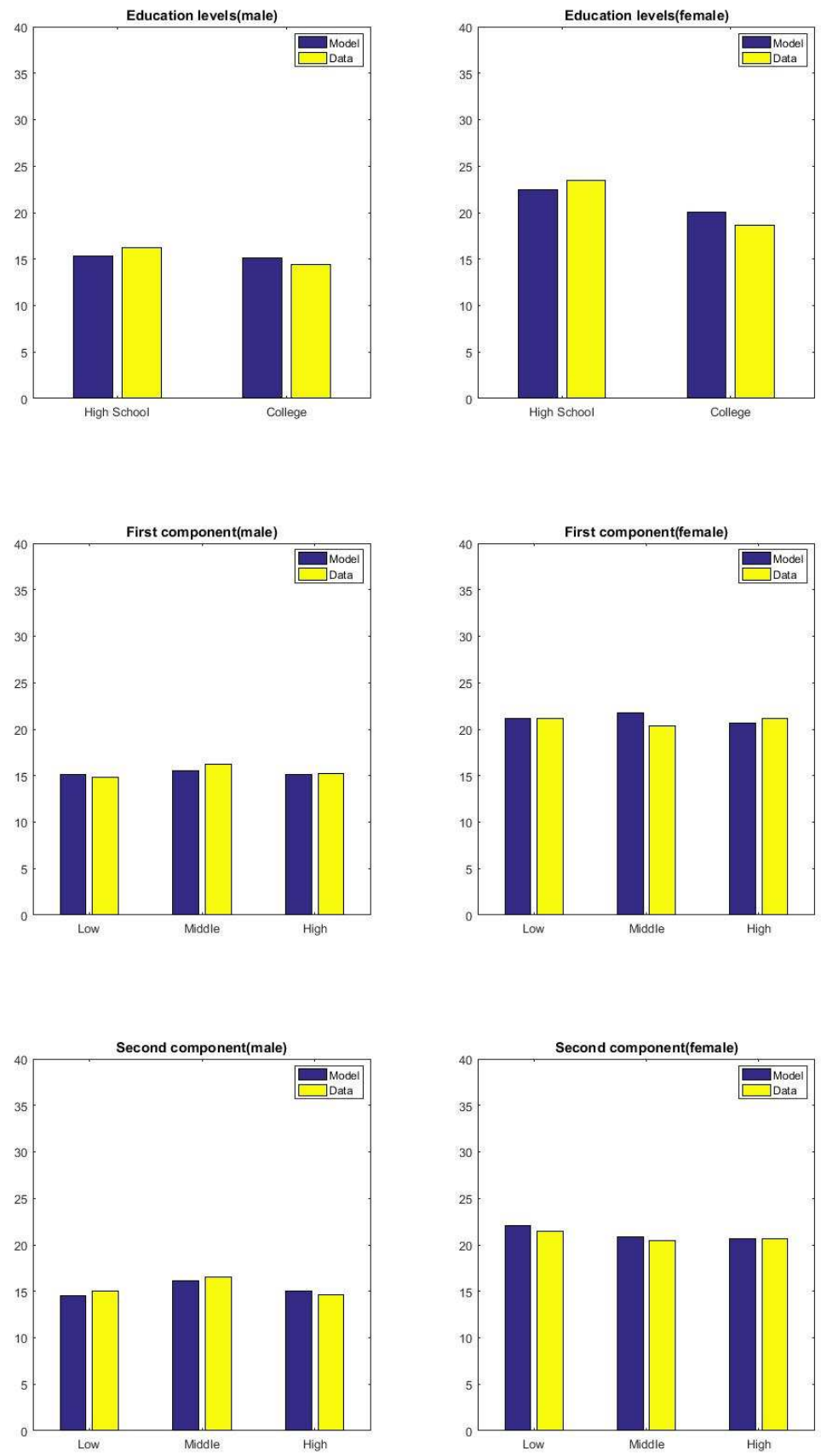
Figure 7: Distributions of accepted wages and offered wages

(a) Male's offered wage and accepted wage

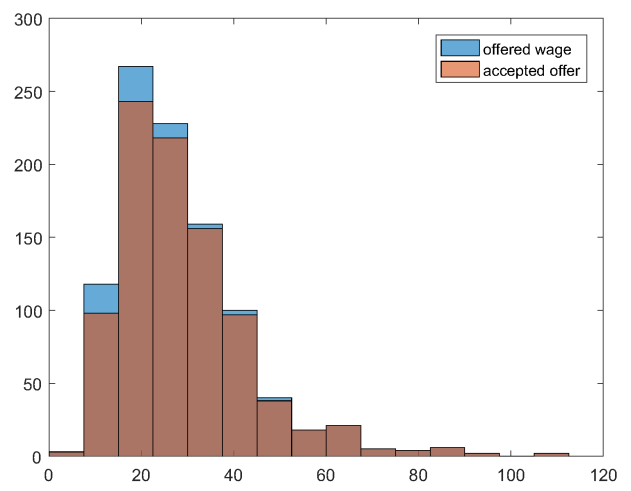

(b) Female's offered wage and accepted wage

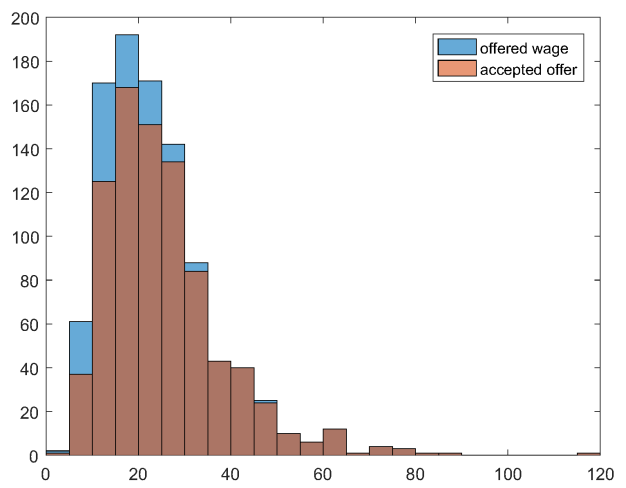

Figure 8: Distributions of accepted wages and offered wages
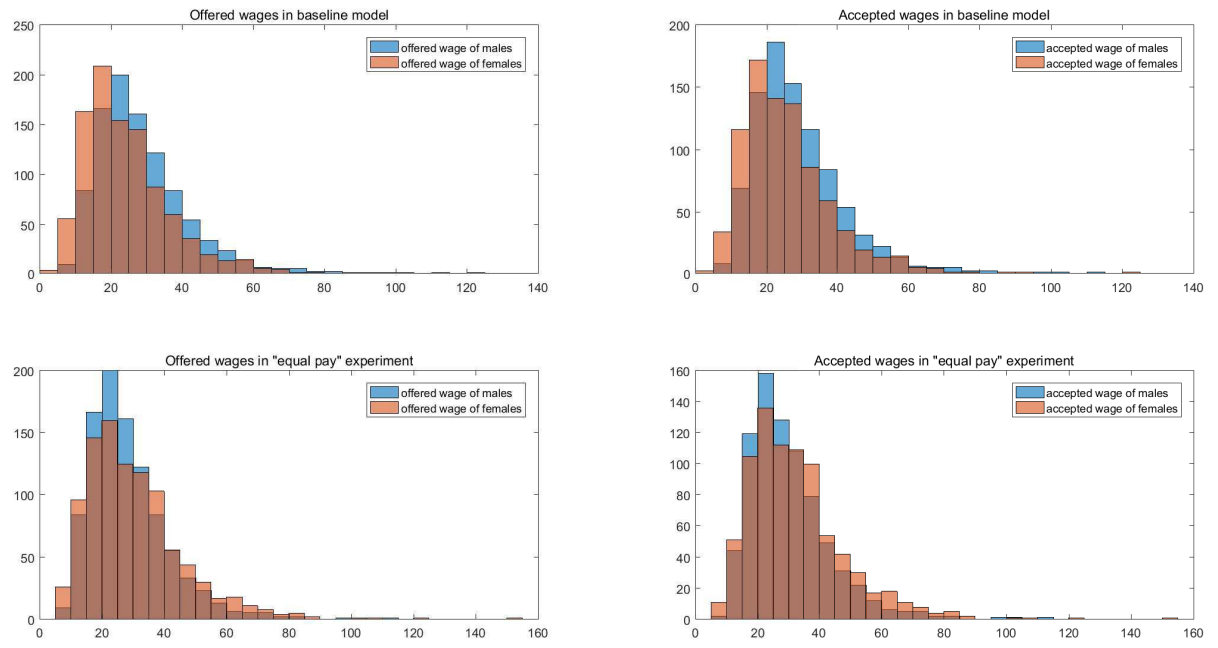